San Jose State University

SJSU ScholarWorks

Master's Theses

Master's Theses and Graduate Research

1994

\title{
The toxicity, absorption, and elimination of selected chromium and selenium compounds in Eisenia Foetida
}

Frances Ann McKenney

San Jose State University

Follow this and additional works at: https://scholarworks.sjsu.edu/etd_theses

\section{Recommended Citation}

McKenney, Frances Ann, "The toxicity, absorption, and elimination of selected chromium and selenium compounds in Eisenia Foetida" (1994). Master's Theses. 935.

DOI: https://doi.org/10.31979/etd.hw32-xe5g

https://scholarworks.sjsu.edu/etd_theses/935

This Thesis is brought to you for free and open access by the Master's Theses and Graduate Research at SJSU ScholarWorks. It has been accepted for inclusion in Master's Theses by an authorized administrator of SJSU ScholarWorks. For more information, please contact scholarworks@sjsu.edu. 


\section{INFORMATION TO USERS}

This manuscript has been reproduced from the microfilm master. UMI films the text directly from the original or copy submitted. Thus, some thesis and dissertation copies are in typewriter face, while others may be from any type of computer printer.

The quality of this reproduction is dependent upon the quality of the copy submitted. Broken or indistinct print, colored or poor quality illustrations and photographs, print bleedthrough, substandard margins, and improper alignment can adversely affect reproduction.

In the unlikely. event that the author did not send UMI a complete manuscript and there are missing pages, these will be noted. Also, if unauthorized copyright material had to be removed, a note will indicate the deletion.

Oversize materials (e.g., maps, drawings, charts) are reproduced by sectioning the original, beginning at the upper left-hand corner and contiming from left to right in equal sections with small overiaps. Each original is also photographed in one exposure and is included in reduced form at the back of the book

Photographs included in the original mamuscript have been reproduced xerographically in this copy. Higher quality $6^{\prime \prime} \times 9^{n}$ black and white photographic prints are available for any photographs or illustrations appearing in this copy for an additional charge. Contact UMI directly to order.

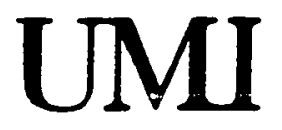

A Bell \& Howell Information Company 300 North Zeeb Road. Ann Arbor. MI 48106-1346 USA 313:761-4700 800:521-0600 
- 
THE TOXICITY, ABSORPTION, AND ELIMINATION

OF SELECTED CHROMIUM AND SELENIUM COMPOUNDS

IN EISENIA FOETIDA

\author{
A Thesis \\ Presented to \\ The Faculty of the Department of \\ Biological sciences \\ San Jose State University
}

In Partial Fulfillment

of the Requirements for the Degree

Master of Science

\author{
by \\ Frances Ann McKenney \\ December 1994
}


UMI Number: 1361193

Copyright 1994 by

McRenney, Frances Ann

All rights reserved.

UMI Microform Edition 1361193

Copyright 1995, by UMI Company. All rights reserved.

This microform edition is protected against unauthorized copying under Title 17, United States Code.

\section{UMI}

300 North Zeeb Road

Ann Arbor, MI 48103 
(C) 1994

Frances Ann McKenney

ALL RIGHT RESERVED 
APPROVED FOR THE DEPARTMENT OF BIOLOGICAL SCIENCES
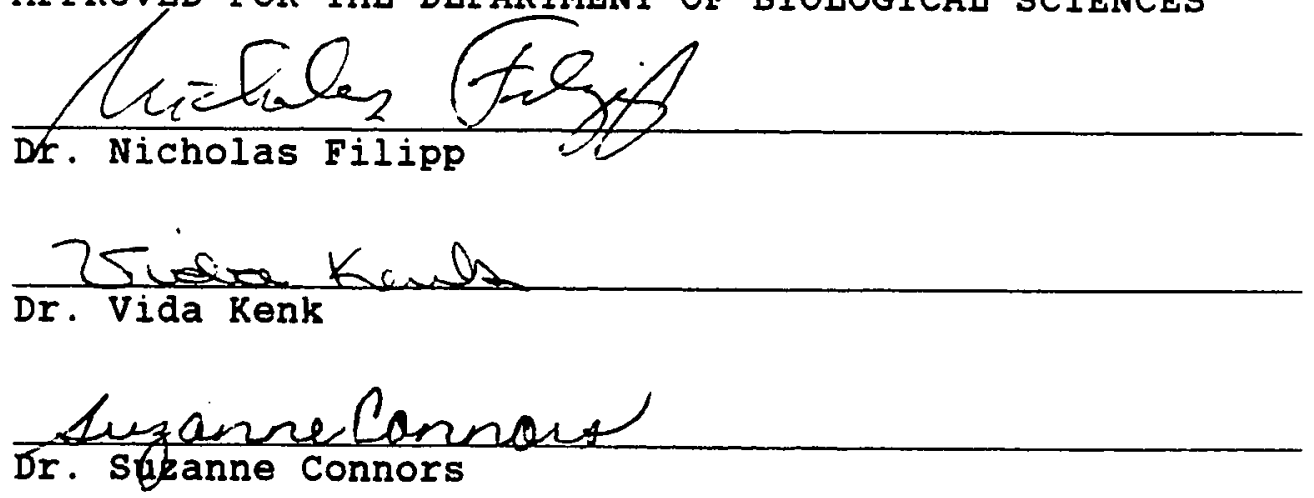

APPROVED FOR THE UNIVERSITY

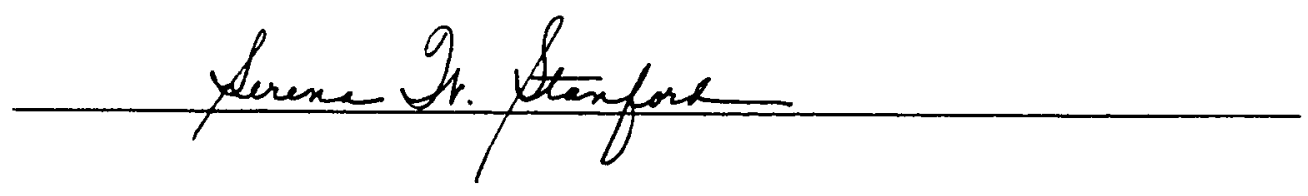




\section{ABSTRACT \\ THE TOXICITY, ABSORPTION, AND ELIMINATION \\ OF SELECTED CHROMIUM AND SELENIUM COMPOUNDS \\ IN EISENIA FOETIDA}

by Frances Ann McKenney

The contact $\mathrm{LC}_{50}$ exposure method is combined with chemical extraction and analysis to determine the toxicity, absorption, and elimination of two chromium compounds, chromium trioxide and chromium chloride, and two selenium compounds, selenium dioxide and sodium selenite, in the earthworm $E$. foetida.

Relative toxicities were determined by $L_{50}$ assays. Absorption efficiencies were determined by exposure to the test agents at various concentrations. The possible effects of absorption efficiency on toxicity are discussed. six week elimination assays were used to determine the half life of elimination for each test agent. The elimination of the chromium test agents and sodium selenite slows considerably after a minimum level of metal is reached. This may indicate that metal retention time is longer than would be anticipated from the elimination half lives. Changes in worm body weight during exposure to the test agent and its possible influence on toxicity are also discussed. 
ACKNOWLEDGEMENTS :

Special thanks to the San Jose State University Foundation which funded this research.

I would like to acknowledge the following people for their help and support:

Mulu Fenta of Philips Semiconductors for many hours of work testing specimens in support of this research.

Javier Alcarez for help with the initial $L_{50}$ experiments and his unending enthusiasm for worms.

Jeanne Morgan of Philips Semiconductors for explaining how to do the chemical extractions and helping me identify the supplies needed.

Shirley Jen of Syntex Research for the donation of various laboratory supplies.

Dr. Arthur Furst, Professor Emeritus of the University of San Francisco, for discussing with me aspects of the study design and for his encouragement.

Denise Dugas, Lucy Morton, Gina LaGalbo, and Dana Finley who washed the glassware, prepared the exposure chambers, and counted and weighed the worms.

Lucy Morton for proof reading the drafts of this document. 
A very special thank you to the members of my thesis committee:

Dr. Vida Kenk for showing me how to identify earthworm species and for asking all the right questions about earthworm husbandry.

Dr. Nicholas Filipp for access to the Chemical Safety Laboratory at Philips Semiconductors and for help determining the appropriate analysis for the specimens.

Dr. Suzanne Connors who was the first professor at SJSU to take an interest in my education; for inspiring me to seek a Masters Degree in Toxicology; and for her continued encouragement and support. Thanks, Dr. Connors, I have enjoyed working with you and have appreciated all your hard work at the university. 


\section{DEDICATION :}

I would like to dedicate this thesis to my family, especialiy to the memory of my parents: To my mother, Rose Margaret Nardin McKenney, who instilled in me a special love for learning; To my father James Wesley Mckenney who died just one week too early to see this thesis completed. I also dedicate this to my sisters, especially Rosemarie who always believes that I can do anything--even if it is not technically possible; and to my nieces and nephews: may you always keep your natural curiosity and openness to the world around you. 


\section{TABLE OF CONTENTS}

Introduction

page 1

Methods and Materials

page 15

Results

page 24

Discussion

page 34

Conclusion

page 43

References

page 47

Tables 1-11

page 54

Figures 1-17

page 66 
LIST OF TABLES

Table $1 \quad L_{5} 0$ Values and Associated Metal Content of Exposure solution

Table 2 Absorption Data Table--Chromium Chloride

Table 3 Absorption Data Table--Chromium Trioxide

Table 4 Absorption Data Table--Selenium Dioxide

Table 5 Absorption Data Table--Sodium Selenite

Table $6 \quad L_{50}$ Ranges and Classification of Toxicity

Table 7A Comparative Weight Table--Chromium Chloride

Table 7B Comparative Weight Table--Chromium Trioxide

Table 7C Comparative Weight Table--Sodium Selenite

Table 7D Comparative Weight Table--Selenium Dioxide

Table 8 Elimination Data Table--Chromium Test Agents

Table 9 Elimination Data Table--Selenium Test Agents

Table 10 Significance of Pre:Post Ratio of Weight

Changes

Table 11 Combined Correlation of Selenium Content of the Test Solutions to the Absorption Efficiency 


\section{LIST OF FIGURES}

Figure 1 Weight Loss During Exposure--Chromium Chloride

Figure 2 Weight Loss During Exposure--Chromium Trioxide

Figure 3 Weight Loss During Exposure--Sodium Selenite Figure 4 Weight Loss During Exposure--Selenium Dioxide Figure 5 Chromium Chloride LC $_{50}$

Figure 6 Chromium Trioxide $\mathrm{LC}_{50}$

Figure 7 Selenium Dioxide $\mathrm{LC}_{50}$

Figure 8 Sodium selenite LC $_{50}$

Figure 9 Chromium Chloride Elimination

Figure 10 Chromium Trioxide Elimination

Figure 11 Sodium Selenite Elimination

Figure 12 Selenium Dioxide Elimination

Figure 13 Chromium Chloride Absorption

Figure 14 Chromium Trioxide Absorption

Figure 15 Selenium Dioxide Absorption

Figure 16 Sodium Selenite Absorption

Figure 17 Combined Selenium Absorption Efficiency-Selenium Dioxide and Sodium Selenite 


\section{INTRODUCTION :}

Various concerns have culminated in the use of earthworms as a biological model for toxicity testing. The increasing number of chemicals that have a potential for introduction into the environment with concomitant exposure to humans necessitates the use of rapid screening tests which can be applied to a variety of chemical classes. The search for standards of environmental quality indicates the need for marker or sentinel species to monitor critical contamination levels in water, air, and soil [1-4]. Social and economic pressures encourage the development of less expensive, non-mammalian animal models. Scientific reason dictates that an alternative model should be used when that model provides the best way to study an isolated effect, to compare effects between species, or to study relationships in systematics. However, the high cost of large animal studies, the need for rapid and easy screening tests, and societal concern for the welfare of laboratory animals have become additional incentives to develop alternative toxicity models [5].

Earthworms have become of increasing interest among researchers using alternative toxicity models. As an alternative model for screening tests, earthworms provide a rapid and inexpensive means of characterizing a variety of chemicals by their relative toxicities [6]. Several methods for controlled chemical exposure in earthworms have been 
used, including soil incorporation [7], injection into the alimentary canal [8], injection into the coelomic cavity [9], and contact exposure on filter paper $[6,10]$. In environmental monitoring, earthworms have been used as sentinel species to determine the biological accumulation of soil contaminants in soil invertebrates and the risk of subsequent introduction to higher trophic levels through the food web. Earthworms have been used to monitor for the persistence of pesticides [11] and heavy metals in the soil $[12,13]$.

The habitat earthworms occupy makes them excellent for use as indicators of soil contamination and in the measurement of the risk of these contaminants entering the food web. There are approximately 1800 earthworm species world-wide, which commonly occupy the first 15 to 35 centimeters of the soil and, in some places, extend their burrows to 1 or 2 meters. They are active in soil construction. They $\mathrm{mix}$ and granulate the soil as they crawl through it ingesting soil particles. As they digest organic matter, they convert soil nutrients to forms usable by plants. They provide vertical mixing of the soil as they pull leaves and other organic substances down from the surface into their burrows. The burrows themselves provide holes for aeration and drainage of the soil [14]. Earthworms also represent a potential point of entry of soil contaminants into the food web. As they burrow through the 
soil, earthworms ingest and absorb contaminants and nutrients from the soil. When an earthworm is eaten by birds, snakes, or small mammals, these nutrients and contaminants are made available to the predator and may be passed through the food web to higher trophic levels, including humans. The risk of exposure to predatory animals posed by soil contaminants is dependent on the concentration and the retention time of the contaminant in the earthworm's tissues.

In their natural habitat, earthworms are exposed to soil contaminants both orally and by absorption through the body wall. The earthworm's porous body wall is designed for the exchange of respiratory gases and moisture. Dissolved contaminants are also transported across the body wall directly into the coelomic cavity [14].

Of the several methods for earthworm exposure listed above, the exposure through soil incorporation and the exposure on filter paper utilize the absorptive properties of the earthworm's body wall as the route of exposure. The contact $\mathrm{IC}_{50}$ method of Roberts and Dorough $[6,10]$ was adapted for the studies presented here. The advantages of this method include its simplicity and ease of execution. Unlike injection, contact exposure is a natural route of exposure in earthworms and therefore can be used as a predictor for environmental exposure. Additionally, Roberts and Dorough [10] have constructed a method for the 
comparison of toxicity between earthworms, rats, and bluegill (a fish). Although the toxicity ratings are not equal between these species, the earthworm Eisenia foetida was found to be equally or more sensitive than rats to seven out of nine pesticides. One of the characteristics necessary in a species to be used for low level screening tests is that the species is equally or more sensitive to toxicity than the test species which must be used in subsequent complex and expensive tests. E. foetida demonstrates this characteristic in the testing of pesticides which confirms $E$. foetida as a good initial screening species for these compounds. The disadvantage of the contact exposure methods used by previous investigators is that, unlike injection methods, the exact delivered dose is not known. This may make this model more useful for environmental modeling and broad spectrum screening tests than for direct extrapolation to higher animals. In environmental modeling, soil analysis can be used to define the exposure concentration. This exposure concentration from the field can be compared to those used in the laboratory. In broad spectrum screening tests it is necessary to have some basis for the comparison of toxicity between chemical compounds. Exposure concentration has been used for this comparison, even when the exact delivered dose is not known. However, the dose in terms of micrograms of test agent per kilogram of body weight (ug/kg) is important 
when extrapolating data to higher animals, including humans. Since the contact exposure method does not provide this information, this type of extrapolation would be inappropriate.

In the method of Roberts and Dorough $[6,10]$, earthworms are exposed to the test agent in individual exposure chambers lined with filter paper. One milliliter of the test agent is dispensed onto the filter paper of the exposure chamber. The exposure dose is measured in micrograms of test agent per square centimeter of exposure surface area $\left(\mathrm{ug} / \mathrm{cm}^{2}\right)$. Groups of ten worms are exposed to logarithmically increasing concentrations from $0.1 \mathrm{ug} / \mathrm{cm}^{2}$ to $1000 \mathrm{ug} / \mathrm{cm}^{2}$. At the end of a 48 hour exposure period, the lethality in each dose group is recorded. The approximate lethal concentration $\left(\mathrm{LC}_{50}\right)$ is the exposure concentration causing death in $50 \%$ or more of the earthworms in that dose group. The test agent is then classified according to the range containing the approximate $\mathrm{LC}_{50}$. Test agents causing 508 or more deaths among exposed earthworms at concentrations less than $1.0 \mathrm{ug} / \mathrm{cm}^{2}$ are classified as supertoxic; 1 to $10 \mathrm{ug} / \mathrm{cm}^{2}$ are extremely toxic; 10 to 100 $\mathrm{ug} / \mathrm{cm}^{2}$ are very toxic; 100 to $1000 \mathrm{ug} / \mathrm{cm}^{2}$ are moderately toxic; and those that have $L C_{50}$ values greater than 1000 ug/ $\mathrm{cm}^{2}$ are classified as relatively nontoxic. Using this method, Roberts and Dorough were able to classify 88 compounds in 8 chemical classes by their relative toxicities 
[6]. This method provides a simple and cost-effective means of ranking the chemicals according to their relative toxicities. However, it provides no information about the rates of absorption or elimination of those chemicals. Information concerning the level of the test agent in the earthworm's tissues and its persistence there is important to the determination of environmental risk.

Bryan and Hummerstone [15] studied the relationship between environmental metal contamination and the concentration of metals in the polychaete worm Nereis diversicolor. These investigators used a nitric acid/hydrochloric acid extraction followed by analysis using atomic absorption spectroscopy to determine the levels of metals in the worm tissue [15]. They found that the concentrations of various metals in the worms' tissues were not always proportional to the concentrations of metals in the surrounding sediment and water. While tissue concentrations of copper and cadmium were proportional to the concentration found in the sediment of the worms' habitat, tissue concentrations of zinc remained constant even for worms in sediments of vastly different zinc concentrations. The investigators postulated that the lack of correlation between the tissue levels of zinc and the environmental levels of $\mathrm{zinc}$ is due to regulation by the tissues of $N$. diversicolor after a certain maximum level is reached. They found no evidence of a regulatory mechanism 
for the uptake of copper or cadmium [15]. This has implications for the food web and gives information important to environmental risk assessment. Birds and other predators may experience greater exposure to copper when feeding on $N$. diversicolor in more polluted water than in less polluted water. However, their exposure to $z$ inc from this food source will not vary with the level of contamination of the water after a certain minimum level of contamination is reached.

The purpose of the study presented here was to develop a method by which the acute toxicity, absorption, and elimination of metallic compounds can be studied in earthworms which are exposed by contact. Chemical analysis of the worms' tissues provides a means of quantifying the delivered dose as a result of contact exposure. The methods of Roberts and Dorough $[6,10]$, and Bryan and Hummerstone [15] have been adapted for this purpose. The 48 hour contact exposure of Roberts and Dorough was initially used to establish the $L_{5} C_{50}$ ranges of these metallic test agents. This allowed the chemicals to be ranked according to their relative toxicities. To determine the absorption of each test agent, earthworms underwent 48 hour contact exposures at various concentrations. Following exposure, the worms were extracted in nitric acid, and analyzed by inductively coupled plasma atomic emission spectroscopy (ICP) to determine the amount of test agent in the worms' tissues. 
To study the elimination of the test agents from earthworm tissues, additional 48 hour exposures were followed by recovery periods of varying lengths, up to six weeks, prior to extraction and analysis.

The species of worm used for the assays reported here was Eisenia foetida. This is one of the most commonly used species for metabolism and toxicity studies $[4,10,16-21]$ and is the species used by Roberts and Dorough for their toxicity screening panel [6]. E. foetida has been recommended by Roberts and Dorough as a superior laboratory animal [10]. It is also the species recommended by the European Economic Community (EEC), which requires that initial toxicity screening of chemicals for EEC legislation be done in earthworms [9].

The test agents used for the $\mathrm{LC}_{50}$, absorption, and elimination assays were chromium chloride, chromium trioxide, selenium dioxide, and sodium selenite. The LC $_{50}$ test method was validated using chemicals previously tested by Roberts and Dorough in their screening tests: formaldehyde, extremely toxic; cadmium chloride, very toxic; ethanol, moderately toxic; and methanol, relatively nontoxic [6].

Chromium and selenium compounds were chosen for this study because of their importance to animals and humans as micronutrients, as well as for their industrial and agricultural significance. A micronutrient is one that is 
normally present in the body in quantities below 0.018 of body weight. The Estimated Safe and Adequate Daily Dietary Intake for adults established by the U.S. National Research Council for both chromium and selenium is 0.05 to 2 milligrams per day [22]. Because of the narrow range in which daily intake is both safe and adequate, exposure to artificial increases in chromium or selenium through agricultural or industrial sources has considerable potential for causing toxicity.

Chromium compounds have oxidation states from divalent to hexavalent. However, only trivalent and hexavalent forms have biologic significance [23]. The trivalent form of chromium, found in chromium chloride, is a required micronutrient [24,25]. Trivalent chromium (chromium III) is required for normal sugar and fat metabolism [26] and is believed to be involved with the glucose tolerance factor $[24,27]$. Dietary deficiency of chromium is associated with maturity-onset diabetes, cardiovascular disease [26], and glucose intolerance [27]. Dietary intake of chromium varies considerably among populations from different countries. In the United States, it is estimated that the average intake of chromium is half of the minimum adequate level [26]. Most foods contain less than $100 \mathrm{ug} / \mathrm{kg}$ of total chromium. However, the chromium content of foods is affected by processing: e.g., use of stainless steel food processing units and contact between acidic fruit juices and steel cans 
increases the chromium content of foods; while cooking with aluminum vessels decreases food chromium content [28]. Hexavalent chromium (chromium VI), found in chromium trioxide, is used industrially in the stainless steel industry, production of chrome pigments, leather tanning and other manufacturing processes. This form poses a hazard for humans. Chromium VI causes skin and respiratory irritation and has been implicated in cancer $[23,29-31]$. Although chromium III is the biologically active form, chromium VI is preferentially picked up by mammalian cells, where it is converted to the trivalent form which then interacts with cellular DNA. Chromium VI induced DNA damage includes DNA interstrand and DNA protein cross linkages and breakage. This causes a disruption of transcription and replication affecting gene expression [32].

Soil chromium content varies across the United states. Chromium III is a naturally occurring mineral in all soils. Its normal range in U.S. soils is 5 to $2000 \mathrm{ppm}$, depending on the chromium content of the parent rock. In contaminated soils from chromite ore residues which have been used for residential landfill, chromium III levels ranged from 5 to $19000 \mathrm{ppm}$ [33]. Several characteristics contribute to chromium III's very low bioavailability in soil: it has very low solubility in water; it has a tendency to form large complexes unsuitable for uptake by plants; and it resists leaching from the soil. These characteristic are $\mathrm{pH}$ 
dependent. At pH higher than 4, chromium III precipitates from aqueous solution and is not carried away by water; at pH below 4, chromium III binds strongly to soil clays [33]. Chromium VI is introduced to the soil through direct atmospheric deposition from industrial releases and other human activities. In contaminated soils, chromium VI represents 1 to 58 of the total chromium. In soils containing chromite ore residues, chromium VI levels range from .5 to $780 \mathrm{ppm}$. Unlike chromium III, chromium VI is freely soluble in water. Chromium VI exhibits some tendency to bind to soil. In experiments of different soil types, chromium VI showed an average of 338 binding to soil [33]. Chromium VI is more mobile in the environment and is more bioavailable than chromium III. These factors coupled with the greater toxicity of chromium VI emphasize the hazard of environmental contamination with chromium VI compounds. The major source of exposure to chromium for birds and mammals is through ingestion. Chromium VI is absorbed more efficiently from the gastrointestinal tract ( 2 to 108) than chromium III (0.5 to 38) [34]. In field studies it has been found that animals from areas with no recognized chromium contamination have tissue concentrations of chromium ranging form 0.1 to $15 \mathrm{ug} / \mathrm{g}$ dry weight. Animals from chromium contaminated areas have tissue levels two orders of magnitude higher [34]. 
In this study the relative toxicities, absorption, and elimination of chromium trioxide (a hexavalent chromium compound) and chromium chloride (a trivalent chromium compound) are compared in $E$. foetida.

Selenium is an essential micronutrient for both animals and humans [35]. In 1989, the U.S. National Research Council established a Recommended Dietary Allowance (RDA) for selenium of 70 micrograms per day for adult men and 55 micrograms per day for adult women [36]. Selenium's main function is as a structural component of bioreactive proteins, including three glutathione peroxidase enzymes. In selenoproteins, selenium replaces the sulfur in cysteine to form selenocysteine [37]. Because of its presence in glutathione peroxidase enzymes, selenium levels affect xenobiotic metabolism [38]. Glutathione peroxidases also function in the protection of cellular membranes from oxidative damage. As an essential component of these antioxidant enzymes, selenium may contribute to anticarcinogenesis $[39,40]$.

Selenium deficiencies and toxicities cause pathologic and teratogenic changes in many animals and birds $[41,42]$. Epidemiologic studies link selenium deficiency to Keshan disease and Kashin-Beck disease. Both human diseases are endemic to selenium-poor areas of China among people who rely on local food sources. Selenium supplements have a direct preventative effect on Keshan disease which confirms 
the causal relationship between selenium deficiency and Keshan disease. Although Kashin-Beck disease is associated with selenium deficiency, which may be a contributing factor, the etiology of this disease is unknown [43]. Selenium is introduced into water and soil by the erosion of natural geologic formations. This natural weathering mobilizes 1000 metric tons of selenium in the U.S. per year [44]. This geologically released selenium may be concentrated by agricultural irrigation [45]. In the U.S., the average selenium concentration of the soil is 0.26 $\mathrm{mg} / \mathrm{kg}$ with large variations among geographic areas [44]. Normal surface water contains $<1$ ug Se/L. Agricultural drainage from affected areas in California have from 140 to $1400 \mathrm{ug} / \mathrm{L}$ [42]. This high level of selenium in the water was associated with a high prevalence of embryonic death and deformity of birds and other wildlife [46].

The toxicity and availability of selenium compounds depend on their chemical form and solubility. Due to geobiologic recycling, selenium is often converted to other chemical forms. Elemental selenium ( $\mathrm{Se} 0$ ) is relatively unavailable biologically. The weathering of elemental selenium produces different products depending on environmental conditions. Under alkaline or oxidative conditions, selenates $(S e+6)$ are formed. Selenates form soluble, highly mobile compounds. Under acidic or reducing conditions, selenites ( $\mathrm{Se}+4$ ) are formed. Selenites form 
stable, immobile compounds and represent a "geologic sink" for selenium. When selenites are exposed to alkaline oxidizing conditions, they are converted to the more soluble selenates [46]. Biologic recycling of selenium also occurs. Selenium is excreted in feces as elemental selenium or metallic selenides and in urine as methylated selenonium ions. When these excretion products are incorporated into soil, the selenium is converted to selenites and selenates by soil bacteria and soil alkalinity or acidity [47]. Although animal droppings do not contain selenium in a bioavailable form, when those droppings are incorporated into soil as fertilizer, the selenium is subjected to biogeochemical conversion to bioavailable forms [44]. Unlike other selenites, sodium selenite, which is often used as a dietary supplement, is highly water soluble and is readily available to biologic systems [42]. There is potential for increasing the amount of selenium reintroduced to soil and water from the droppings of cattle treated with this supplement. Selenium dioxide $(S e+2)$ is a soluble compound which oxidizes to selenate or selenite. Like elemental selenium, its bioavailability is expected to be very low. The toxicity, absorption, and elimination of sodium selenite which has high bioavailability is compared to that of selenium dioxide with its low bioavailability. 


\section{Methods and Materials}

Test Animals:

Earthworms were purchased from Angler's Bait and Tackle, Fremont, California. These were sold under the name "redworms". The redworms were positively identified as Eisenia foetida using the key of Edwards and Lofty [14]. Prior to exposure, the worms were group-housed at room temperature in plastic boxes with non-sealing lids. Steam sterilized potting soil, obtained from the Woolworth's Nursery in Menlo Park, California, was used as a housing medium. Water was added as necessary to keep the housing medium damp but not wet. The worms were fed pureed carrots mixed with straw or fine cobb meal to provide fiber and to absorb moisture.

At the end of all studies, any surviving worms which were not used for chemical analysis were euthanized. No previously exposed worms were used for any additional study.

Test Materials:

The test agents were purchased from sigma. These were chromium (VI) trioxide $\left(\mathrm{CrO}_{3}\right)$, chromium (III) chloride $\left(\mathrm{CrCl}_{3}\right)$, selenium dioxide $\left(\mathrm{SeO}_{2}\right)$, and sodium selenite $\left(\mathrm{Na}_{2} \mathrm{SeO}_{3}\right)$.

The exposure doses were prepared to provide exposure concentrations of micrograms of test agent per square centimeter of exposure chamber surface area $\left(\mathrm{ug} / \mathrm{cm}^{2}\right)$. For the $\mathrm{LC}_{50}$ studies, the doses increased logarithmically from 
0.1 to 1000 micrograms of test substance per square centimeter. Aqueous solutions of the test materials were made. Delivery of each dose was in one milliliter volumes. Since the surface area of the exposure chamber is $65 \mathrm{~cm}^{2}$, the actual concentration of the test substance used for the $1000 \mathrm{ug} / \mathrm{cm}^{2}$ exposure was $65000 \mathrm{ug} / \mathrm{ml}$ :

$$
\frac{1000 \mathrm{ug}}{\mathrm{cm}^{2}} \times \frac{65 \mathrm{~cm}^{2}}{1 \mathrm{ml}}=65000 \mathrm{ug} / \mathrm{ml}
$$

The remaining test solutions of lower dose levels were made by serial dilution of the $1000 \mathrm{ug} / \mathrm{cm}^{2}$ test solution. The test solutions for absorption and elimination studies were made by making the required dilutions from the $1000 \mathrm{ug} / \mathrm{cm}^{2}$ test solution. Tables 1 through 5 show the concentration of test substance used for the exposure of each assay, with their associated chromium or selenium content.

\section{Exposures:}

Exposure for all assays was by contact in exposure chambers according to the procedure of Roberts and Dorough [6]. An exposure chamber consisted of a $2.2 \mathrm{x} 9.5 \mathrm{~cm}$ glass shell vial lined with Number one whatman filter paper cut to $6.9 \times 9.4 \mathrm{~cm}$. The filter paper, with a surface area of 65 $\mathrm{cm}^{2}$ was the exposure surface. One milliliter of test solution of the appropriate concentration was pipetted onto the filter paper of each labelled vial. One milliliter of 
deionized water was used for unexposed controls. During exposure, the vial was capped with a porous cork.

Earthworms were removed from the housing medium, gently rinsed in deionized water, and blotted on paper towels to remove excess housing medium and water. The earthworms of each exposure group were weighed together and the preexposure group weight was recorded. One worm was put into each of the prepared exposure chambers. The exposure chambers were capped and stored horizontally in the dark for 48 hours. At the end of the 48 hour exposure period, the worms were remuved from the exposure chambers. They were gently rinsed in deionized water and blotted on paper towels. This was done to remove any test material that may have been adhering to the worms' surfaces but was not actually absorbed. Further handling of the worms after exposure is described below for each type of assay.

\section{LC 50 Assays:}

For each $\mathrm{LC}_{50}$ assay, sixty worms were used. Each worm was randomly assigned to one of six groups. Each group was comprised of 10 worms. The control group was exposed to deionized water only. The remaining five groups were each exposed to one of the logarithmically increasing exposure levels from 0.1 to $1000 \mathrm{ug} / \mathrm{cm}^{2}$ (Table 6).

At the end of the 48 hour exposure period, the numbers of living and dead worms for each exposure group were recorded (Table 6). According to the procedure of Roberts 
and Dorough, a worm is counted as dead if it does not respond to gentle probing of its anterior end. Worms respond to an irritating environment by pinching off and losing posterior segments. A worm that loses a significant number of posterior segments but shows movement when probed is scored as alive [6]. The post-exposure weight of the survivors of each group was recorded. Only the intact anterior portion of those worms that had lost segments was included in the post exposure weights.

Using the survival information of each exposure group from the $\mathrm{LC}_{50}$ assays, the test agents were classified (Table 1) according to the system devised by Roberts and Dorough [6].

\section{Absorption Assays:}

For each absorption assay, 320 worms were used. Forty worms were randomly assigned to each of eight groups. The control group was exposed to deionized water only. The exposure levels of the remaining seven groups were made to span the $\mathrm{LC}_{50}$ range and one log dose below the $L C_{50}$ range for each test agent (Tables 2-5).

At the end of the 48 hour exposure period, the number of survivors for each exposure group was recorded using the same criterion for death as was used for the $L_{50}$ studies (Tables 2-5). The post-exposure weight of the survivors for each group was recorded (Table 7). Groups having fewer than 15 survivors were discarded and no chemical analysis was 
done. Groups with 15 or more survivors were immediately prepared for extraction and chemical analysis as described under the Extraction and Analysis sections below.

Elimination Assays:

For each elimination assay, 640 worms were used. Forty worms were randomly assigned to each of sixteen groups. Two groups served as controls and were exposed to deionized water only. The treated groups were exposed to $1 \mathrm{ug} / \mathrm{cm}^{2}$ of the test agent.

At the end of the 48 hour exposure period, surviving worms from each group were counted, rinsed in deionized water, and weighed. Since the elimination assays depend on post-exposure survival of the worms, obviously moribund worms were not counted as survivors. Each of the sixteen groups was designated to be harvested at a specified time after exposure. One control group and one exposed group were harvested immediately at the termination of exposure and were prepared for extraction and chemical analysis as described below. The control group was used to measure endogenous chromium or selenium in the worms.

Each of the remaining groups was placed into a labelled cardboard bait tub containing the housing medium and food, and was stored at room temperature. One group was harvested at each of the specified endpoints: 12 hours; daily from one to seven days; and approximately weekly for six weeks. The remaining unexposed control group was used to determine the 
long-term survival rate that could be expected from worms housed in this manner.

At each specified endpoint, worms were removed from the housing medium, gently rinsed clean of the housing medium in deionized water, and blotted on paper towels to remove excess water. The number of survivors and the group weight for each endpoint group were recorded. The criterion for death at endpoint was the same as that used for $\mathrm{LC}_{50}$ studies. If a group had 35 or more survivors, all survivors were prepared for extraction and chemical analysis. If 20 to 35 survivors were present, only 20 were prepared for extraction and chemical analysis. The unused worms were returned to the housing medium. When fewer than 20 worms survived in a group at endpoint, worms from other groups were taken to provide a minimum of 20 worms for extraction and chemical analysis. If there were insufficient worms left in the study to make the requisite number, the study was terminated. This was done to keep the matrix of the extracted specimens as consistent as possible (Tables 8-9).

\section{Extraction:}

Each group of worms being prepared for extraction and chemical analysis was euthanized by freezing at $-20^{\circ} \mathrm{C}$ for 30 to 60 minutes. Euthanized worms were stored in the freezer until analysis. The specimens were allowed to come to room temperature, and dried in an incubator at $85^{\circ} \mathrm{C}$ for 24 hours. The dry weight of each specimen was recorded. 
The extraction method used on these specimens was modified from that of Bryan and Hummerstone [15]. Fifty milliliters of concentrated nitric acid was added to each dried specimen containing 29 to 40 worms; and 25 milliliters to each specimen containing fewer than 29 worms. One milliliter of 308 hydrogen peroxide per 25 milliliters of nitric acid was added to specimens from selenium exposed assays. The specimens were covered with a watch glass and allowed to reflux on a laboratory hot plate until no further visible color change occurred. The specimens were not allowed to boil but were kept at a temperature warm enough to cause condensation of the acid on the watch glass. When no further change was evident, the watch glasses were removed and the specimens were allowed to evaporate. Chromium specimens were evaporated to near dryness; selenium specimens to approximately $5 \mathrm{ml}$. Each specimen was transferred to a labelled volumetric flask by rinsing the extraction beaker and watch glass several times with 28 nitric acid. The specimen was then brought to final volume in 28 nitric acid: specimens consisting of 29 to 40 worms were brought to a final volume of $50 \mathrm{ml}$; those of 28 or fewer worms to $25 \mathrm{ml}$. The specimens were then stored at 0 to $5^{\circ} \mathrm{C}$ until chemical analysis could be done. 


\section{Chemical Analysis:}

Specimens containing chromium exposed worms were diluted $1: 10$ in 28 nitric acid. The selenium exposed specimens were not diluted. These specimens were analyzed by inductively coupled plasma (ICP) in an Atom scan 25 by Thermo Jerrel Ash. The limit of detection for chromium by this method is $2 \mathrm{ug} / \mathrm{L}$; for selenium, $200 \mathrm{ug} / \mathrm{L}$.

known amounts of the test agents were added to specimens containing unexposed worms. These were diluted to serve as matrix references and to determine the percent recovery of the extraction and analysis methods. This information was used to adjust the final chromium or selenium content of each specimen.

statistics:

Correlation between bivariate variables was determined using Pearson's Product Moment Coefficient. Linear correlation was accepted at the 95 confidence level. The null hypothesis for these comparisons was no linear correlation between variables $\left.\left[H_{0}:\left(y_{1}-y_{2}\right)\right\rangle_{<} m\left(x_{1}-x_{2}\right)\right]$. The extrapolated values given for $L C_{50}$ are expressed with their associated 998 confidence interval (Table 1). No transformation of values was done when linear correlation existed at the acceptable 958 confidence level. Transformations to log values were used when the linear correlation of untransformed bivariate data was at, or 
below, the $95 \%$ confidence level; or whenever a scattergraph of the data suggested a relationship other than linear. Univariate data, i.e. specimen weights, were evaluated by mean and standard deviation (Tables 7A-7D). The significance of weight changes was determined by using the Student's t-test for comparison of means. Means are given with their 998 confidence intervals (Table 2). Weight changes were accepted as significant at the $95 \%$ significance level. 


\section{RESULTS}

Specimen Observations:

Exposed worms exhibited three behaviors that effectively resulted in the reduction of their exposed surface area and may have reduced their contact with the test agents. The first behavior, seen in chromium exposed worms was a tight coiling of the worms' bodies. This was especially evident in chromium trioxide exposed worms. It was not observed in selenium exposed worms.

The second surface-reducing behavior was observed in worms exposed to the chromium test agents at concentrations above the $\mathrm{LC}_{50}$. These worms responded by dropping posterior segments. Loss of segments was not seen in selenium exposed worms. Although this response was not seen at the termination of exposure in the elimination and absorption assays, it was noted in one preliminary exposure during a pilot run for the elimination assays. In this preliminary exposure, worms were exposed to $10 \mathrm{ug} / \mathrm{cm}^{2}$ of chromium chloride (one log dose higher than that used for the elimination assay presented here). Segment loss was observed in these worms during the first week post-exposure.

A third response worms may exhibit to irritating stimuli is the thickening of the normal mucus layer that covers the external surface of each worm. This protective mucus layer inhibits direct contact with the irritating environment $[6,14]$. To produce the protective mucus layer, 
the worm draws on its body's moisture content. It has been noted that worm body weight may fluctuate by as much as 708 in normal response to environmental factors. Much of this weight variation is due to the absorption and loss of moisture [14]. Changes in the mucus layer were not discernible except in chromium chloride exposed worms. These specimens had a dry appearance. In the preliminary elimination assay for chromium chloride noted above, the worms never regained their normal moist appearance. There was also permanent damage to their cuticles. Within four days after the termination of exposure, the cuticle was seen to lie in shreds along the worms' surfaces. The worms never regained vigor and by the end of the second week $30 \%$ of the worms were dead. The worms exposed at $1 \mathrm{ug} / \mathrm{cm}^{2}$ of chromium chloride for the elimination assay included in this study also had the dry appearance at the termination of exposure. However, by the end of the first week post-exposure, the worms had regained their normal appearance. This phenomenon is further discussed below in the comparison of pre-exposure to post-exposure weights.

Comparisons between the pre-exposure and post-exposure weights of each specimen give an indication of the gain or loss of moisture that may have been used in the production of the protective mucus layer. Tables $7 \mathrm{~A}$ to $7 \mathrm{D}$ show the average pre-exposure and post-exposure weights of each specimen in the absorption assays. The ratio of pre- 
exposure weight to post-exposure weight was used as a basis for the comparison of weight changes. Using the student's $t$-test for the comparison of two means, the significance of the weight changes was determined in comparison to the average weight change of all controls [Table 10]. Both chromium test agents caused a statistically significant decrease in weight in the exposed worms over the controls during the elimination assay exposures. Comparisons of absorption assay data show that for chromium chloride this weight loss correlated with the log of the exposure concentration (Figure 1). This means that the rate of weight loss accelerated with increasing exposure concentration. If this weight loss was due to moisture loss it is possible that chromium chloride accelerated the destruction of the protective mucus layer. Increasing amounts of moisture were lost as the worms attempted to reestablish the mucus layer. The decrease in weight caused by chromium trioxide correlated to the exposure concentration without log transformation (Figure 2). Sodium selenite caused a decrease in weight over the controls during the elimination assay exposure; however, it did not correlate to the exposure concentrations in the absorption assay (Figure 3). Selenium dioxide caused no statistically significant change to specimen weights (Table 10; Figure 4). 


\section{Extraction Controls}

For each test agent, unexposed controls were extracted and analyzed to measure the background or endogenous levels of chromium or selenium in the extracted specimens. Significant background levels of selenium were found in these controls ranging from 15.18 to $26.56 \mathrm{ug} \mathrm{se} / \mathrm{g} \mathrm{dry}$ weight. For each absorption or elimination assay, the associated background selenium concentration from the negative control was subtracted from the exposed specimens. No measurable amount of chromium was detected in the unexposed chromium controls.

Additionally, for each test agent, a series of controls containing known amounts of the test agents was used to determine the percent recovery of the extraction and analysis methods and the degree of matrix interference. The percent recovery varied with the dilution of the specimens and with the concentration of metal in the control for each test agent. This probably indicates interactions with the matrix. The approximate percent recovery for each test agent was determined using the matrix controls that had concentrations and dilution factors similar to the exposed specimens. The respective percent recoveries for each test agent are listed in the Absorption Data tables (Tables 2-5). LC 50 Assays:

The original $L_{50}$ exposures were used to establish the $\mathrm{LC}_{50}$ range for each test agent (Table 6). Lethality 
information from the absorption study exposures was used to determine a precise $\mathrm{LC}_{50}$ value (Table 1 ). Linear correlation between exposure concentration and lethality for each test agent was very strong, exceeding the 958 confidence level. Consequently, no transformation of data was necessary and $L C_{50}$ values were found by simple linear regression by the method of least squares (Figures 5-8).

The original test solutions were prepared calculating the micrograms of whole test agent per surface area. However, since toxicity is assumed to be related to the amount of metal ions present, the chromium or selenium content of the exposure solution is also reported. The metal content is determined by multiplying the concentration of the test solution by its respective metal's mole fraction. The $\mathrm{LC}_{50}$ data for each test agent, including the associated chromium or selenium content of the exposure solution, are summarized in Table 1 .

\section{Absorption Assays:}

The absorption assays were used to determine the relationship between the exposure concentration and the amount of chromium or selenium absorbed by the specimens for each test agent. Due to the variation in number and size of worms among specimens, the final specimens represented different concentrations of worm tissues. So that comparisons could be made among specimens, it was necessary to normalize them to worm content. Since the live weight of 
worms varied significantly over the life of each worm, neither the live weight nor the number of worms were adequate for this normalization. The dry weight was chosen as the characteristic most representative of the amount of worm present in each specimen. The concentration of each specimen was converted to micrograms of chromium or selenium per gram dry weight of worm $(u g / g)$. This was done by multiplying the concentration of each specimen by its final volume after extraction to find the total selenium or chromium in the specimen. This number was then divided by the dry weight of the specimen. The resulting value in ug/g represents the amount of selenium or chromium absorbed by the specimen. This information is contained in the Absorption Data Tables (Tables 2-5) under the Body Burden column.

$$
\frac{[\mathrm{C}] \mathrm{X}[\mathrm{VE}]}{\mathrm{W}_{\mathrm{d}}}=\mathrm{Y},
$$

where $\mathrm{C}$ is the concentration ( $\mathrm{ug} / \mathrm{L}$ ) of the specimen detected by ICP; $V^{f}$ is the final volume (L) of the specimen after extraction; $W_{d}$ is the dry weight $(g)$ of the specimen; and $Y$ is the resulting micrograms of selenium or chromium per gram dry weight of worm. This value represents the absorption of each specimen. For each of the test agents presented here, the amount of chromium or selenium absorbed was directly proportional to the exposure concentration and the linear correlation was within the 958 confidence level. 
An additional comparison was made for each test agent between the amount of chromium or selenium available to each specimen during exposure and the associated percent

absorption. The amount of chromium or selenium available is the number of micrograms each worm was exposed to multiplied by the number of worms in the specimen.

$$
\left[C_{T}\right] \times \frac{M W}{F W} \times V_{E}=C_{m f} \quad \text { and } \quad C_{m f} \times n=M
$$

Where $C_{T}$ is the concentration (ug/L) of test agent in the exposure solution; $M W$ is the atomic weight of chromium or selenium; $F W$ is the formula weight of the test agent; $V_{E}$ is the volume $(.001 \mathrm{~L})$ of the test agent used for exposure; $\mathrm{C}_{\mathrm{mf}}$ is the mole fraction (ug) of metal; $n$ is the number of worms in the specimen; and $M$ is the amount ( $u g$ ) of metal available during exposure to the entire pooled specimen.

The percent absorption is found by dividing the total micrograms of selenium or chromium detected in the specimen by this total amount available during exposure.

\section{$\frac{[C] \times[V f] \times 100}{M}=8$ Absorption}

Where $C$ is the concentration (ug/L) of the specimen detected by ICP; $\mathrm{V}^{f}$ is the final volume (I) of the specimen after extraction; $M$ is the amount (ug) of metal available during exposure. The percent absorption is a measure of absorption efficiency. For the two selenium compounds and chromium trioxide, a linear correlation was found between the log of 
the available selenium or chromium and the absorption efficiency that had a correlation within the 958 confidence level. For chromium chloride, a strong linear correlation was found without $\log$ transformation. All absorption assay data are summarized in the Absorption Data Tables (Tables 25).

\section{Elimination Assay:}

Elimination for the two chromium test agents and sodium selenite progressed in two phases. During the first phase, there was relatively rapid constant elimination which lasted through the first two weeks post-exposure. However, after the second week, a second phase is evident during which elimination declined and body burden of metal became constant (Figures 9-11). The elimination of selenium dioxide remained constant during the six weeks of the study (Figure 12)

The data from the elimination assays were used to determine the half-life of elimination for each test agent. As was done for the absorption assays, the amount of chromium and selenium in each specimen of the elimination assays was normalized to the gram dry weight of worm in the specimen to give an indication of the body burden of the metals in the worms. For each test agent, there is strong linear correlation between post-exposure recovery time and the body burden of metal expressed as micrograms of chromium or selenium per gram dry weight of worm, without any 
transformations of the data (Tables 8 and 9). The initial body burden $\left(C_{0}\right)$ of chromium or selenium and the final body burden $\left(C_{f}\right)$ at the end of phase I elimination were determined by regression of the elimination assay phase I data. The initial tissue concentration value $\left(C_{0}\right)$ was divided by two to determine the body burden equal to half the initial concentration $\left(c_{1 / 2}\right)$. The coefficient of elimination ( $k$ ) was determined by the following equation:

$$
k=\left[\operatorname{LnC} C_{0}-\operatorname{Ln} C_{f}\right] / t
$$

where $C_{0}$ is the statistically determined initial chromium or selenium concentration; $C_{f}$ is the statistically determined final concentration; and $t$ is the time post exposure. The half life of elimination was then determined by the equation [48]:

$$
t_{1 / 2}=.693 / \mathrm{k}
$$

The half-life of elimination, expressed in days for each of the test agents, is shown in Tables 8 and 9.

The graphs of the elimination data for the two chromium compounds (Figures 9 and 10) show that chromium is not eliminated to any significant extent after the first two weeks during phase II elimination. The body burden of chromium in the three week to six week specimens remained relatively constant, as shown by the mean and standard deviation of these values found in Table 8 . The elimination of selenium dioxide continued in a linear fashion throughout the six weeks of the study (Figure 12). However, the 
elimination of sodium selenite, like that of the chromium test agents, diminished after the second week (Figure 11). The mean and standard deviation of the selenium body burden for sodium selenite from weeks three to six, confirm that the body burden of selenium remains constant (Table 9). 
Discussion:

Chromium:

On the basis of their respective $\mathrm{LC}_{50}$ ranges, chromium chloride was classified as very toxic, while chromium trioxide was classified as extremely toxic (Table 6). However, when the actual chromium contents of the test solutions were compared, there was not as significant a difference in the toxicities. The $\mathrm{LC}_{50}$ of chromium chloride was $19.07 \mathrm{ug} / \mathrm{cm}^{2}$, which has an associated chromium content of $6.26 \mathrm{ug} / \mathrm{cm}^{2}$. This was found by multiplying the $\mathrm{LC}_{50}$ value by the mole fraction of chromium in chromium chloride:

$$
19.07 \times \frac{51.996 \mathrm{Cr}}{158.355 \mathrm{CrCl}_{3}}=6.26
$$

Chromium trioxide's $\mathrm{LC}_{50}$ of $6.19 \mathrm{ug} / \mathrm{cm}^{2}$ has an associated chromium content of $3.22 \mathrm{ug} / \mathrm{cm}^{2}$ (6.15 x 51.996/99.9942). Conversion of the $\mathrm{LC}_{50}$ values to the chromium content allowed a comparison of the test agents according to the contribution the metal makes to compound's toxicity. These chromium contents are not as dissimilar as the $\mathrm{IC}_{50}$ values. Classification based on chromium content values would place these two chromium test agents in the same toxicity class: extremely toxic. The worms were twice as sensitive to the chromium in chromium trioxide as they were to that of chromium chloride. This comparison of the $\mathrm{LC}_{50}$ values for chromium chloride and chromium trioxide indicated that the lethality for each of these test agents was dependent on the 
chromium content of the agent as well as on its chemical form. If the toxicity were dependent on the chemical form alone, it would be expected that the chromium contents of the $L_{50}$ values would have been more disparate.

Absorption for each of the chromium test agents increased with increasing exposure concentration (Figures 13 and 14) showing a significance level greater than 958 (Tables 2 and 3 ). However, the correlation was particularly strong for chromium chloride for which the correlation was within the 998 confidence level. This may be due to the respective absorption efficiencies of the two agents. The absorption efficiencies varied with the chemical form as well as with the chromium content. The absorption efficiency for chromium chloride increased with increasing exposure concentration (Figure 13), contrasting with that for chromium trioxide which decreased (Figure 14). This culminated in chromium trioxide being absorbed more efficiently at exposure concentrations less than $1 \mathrm{ug} / \mathrm{cm}^{2}$ and chromium chloride being absorbed more efficiently at concentrations greater than $1 \mathrm{ug} / \mathrm{cm}^{2}$. Since the absorption efficiency for chromium trioxide correlated with the log of the chromium content, the absorption efficiency was decreasing at an accelerated rate for this test agent. Chromium trioxide is a caustic substance that burns living tissue. The increasing exposure concentrations of this test agent may have caused an increase in tissue death. The dead 
tissue was unable to transport or allow diffusion of more of the agent into the worm's body. This may also be a factor in the death of the worms, as the damaged tissue would likewise be unable to transport respiratory gases and water. The chromium trioxide exposed worms were observed to form tight coils which effectively reduced their surface area. This, too, could contribute to the accelerating decrease in absorption efficiency.

The above not withstanding, there was no evidence for tissue regulation of chromium beyond the physical barrier presented by chromium trioxide damaged tissue. It is evident that if a regulating mechanism exists for chromium absorption, it is not effective at the concentrations tested here. As a result, the body burden of chromium was dependent on the exposure concentration of the test agent and the chemical form of chromium.

Chromium chloride exposed worms showed an accelerating decrease in body weights which correlated to the log of the exposure concentration (Table 10; Figure 1). The weight loss seen in the chromium trioxide exposed worms correlated directly to the exposure concentration without log transformations (Table 10; Figure 2). If weight loss is considered a measure of mucus protection, the chromium chloride exposed worms should have produced more mucus. However, these worms appeared dry immediately post-exposure. It is possible that the chromium chloride caused the 
breakdown of the mucus that was produced. This would explain both the greater weight loss in the chromium chloride exposed worms, and their dry appearance.

The elimination assays for the chromium test agents showed a statistically significant linearity between the post-exposure time and the body burden of chromium during phase I elimination (Table 8 ). This linear relationship suggests that elimination of chromium during phase I elimination follows zero order kinetics: a fairly constant amount of chromium is eliminated per unit time, independent of the body burden of chromium. The half-lives of elimination for these two test agents differed by approximately one week: 6.34 days for chromium chloride and 15.8 days for chromium trioxide. The graphs of the elimination data show that at approximately two weeks elimination of chromium slows considerably for both test agents (Figures 9 and 10). The body burden of chromium from chromium trioxide stabilized at a higher level than that from chromium chloride: the average body burden after two weeks for chromium trioxide exposed worms was $11.16 \mathrm{ug} / \mathrm{g}$; the average body burden for chromium chloride was $6.51 \mathrm{ug} / \mathrm{g}$. This seems to indicate that the worms not only have a limited ability to rid themselves of chromium, but this ability is affected by the chemical form of chromium. Also, the presence of a phase II elimination indicates that the 
chromium may remain in the worm's tissues longer than is implied by the half-lives of elimination of the test agents.

Selenium:

Like the chromium compounds discussed above, the two selenium test agents also fell into different toxicity classifications on the basis of the initial $\mathrm{LC}_{50}$ assays: selenium dioxide was classified as extremely toxic while sodium selenite was classified as very toxic (Table 6). However, in contrast to the chromium test agents, the toxicity classification of the selenium compounds remains unchanged whether one uses the test agent concentrations or the selenium contents of the test solutions. Selenium dioxide had an $\mathrm{LC}_{50}$ of $7.03 \mathrm{ug} / \mathrm{cm}^{2}$ which has an associated selenium content of $5.00 \mathrm{ug} / \mathrm{cm}^{2}(7.03 \times 78.96 / 110.9588)$. The $\mathrm{LC}_{50}$ for sodium selenite was $24.4 \mathrm{ug} / \mathrm{cm}^{2}$ with an associated selenium content of $11.14 \mathrm{ug} / \mathrm{cm}^{2} / 24.4 \mathrm{x}$ $78.96 / 172.93774)$. The worms were less tolerant of selenium dioxide than of sodium selenite. Selenium toxicity was dependent on the amount of selenium present as well as its chemical form.

Although the absorption of selenium from each of the selenium test agents was directly proportional to the exposure concentration, increasing with increased exposure concentration, the absorption efficiency of each was indirectly proportional, decreasing with increased exposure concentration (Figures 15 and 16). The correlation was 
between the log transformed selenium content values and the absorption efficiencies (Tables 4 and 5 ). This indicated that the absorption efficiencies of these test agents decreased at an accelerating rate as the exposure concentration increased. When the absorption data from these two test agents was combined, there was a very strong correlation between the log of the selenium content of the test agent (regardless of source) and the absorption efficiency $(p<0.0005)$ (Table 11; Figure 17). This indicated that the absorption efficiency was affected entirely by the amount of selenium present and not the chemical form of selenium. Since selenium dioxide can be oxidized to selenite under alkaline conditions, it is possible that such an oxidation occurred at the point of absorption. This may have been aided by the alkalinity of the worms protective mucus layer. However, this does not explain why selenium dioxide was approximately twice as toxic as sodium selenite in the $\mathrm{LC}_{50}$ assays. The difference in toxicity is not due to respective availability of selenium and must have been due to the chemicai form of the test agent. The mechanism responsible for the oxidation of the selenium dioxide may be involved in the lethality of worms exposed to selenium dioxide. This hypothesis would be an interesting topic for future study. Also, if the worms are oxidizing selenium to more bioavailable forms, earthworms may have a significant effect on the mobilization of selenium in the soil. 
The weight loss experienced by selenium exposed worms during the absorption and elimination assay exposures showed a trend toward increasing weight loss with increasing exposure concentration (Figure 3-4). However, this weight change was statistically significant only for sodium selenite (Table 10).

Since selenium exposed worms did not coil or lose segments, surface area regulating behaviors cannot be credited with the decreasing absorption efficiency of the selenium test agents. Nor is there evidence of tissue damage, which may have impeded the penetration of the worms' body walls by selenium. In the absence of other factors that may have affected the absorption efficiency, it is possible that there is a tissue mechanism responsible for the decrease of absorption efficiency of these selenium test agents. If such a mechanism exists, it did not limit the final body burden of selenium at the exposure concentrations tested, but it did regulate the rate of selenium uptake. This may indicate saturation of a transport mechanism at higher selenium concentrations.

The data from the elimination assays for the selenium test agents (Table 9) showed a linear relationship between time and body burden of selenium for each of the test agents. For sodium selenite, this correlation existed for phase I elimination which included the first two weeks of the study. For selenium dioxide, which had constant 
elimination, the correlation existed throughout the six weeks of the study. This linear relationship between time and body burden indicated that the elimination of selenium, like that of chromium, followed zero order kinetics. However, the half-lives of elimination of the two selenium test agents were significantly different. The half-life of selenium dioxide, 42.01 days, was approximately six times as long as that of sodium selenite, 7.32 days. This was not influenced by the respective initial body burdens of selenium. Sodium selenite exposed groups had an initial body burden $\left(C_{0}\right)$ of $28.90 \mathrm{ug} / \mathrm{g}$, while selenium dioxide exposed groups had an initial body burden of $30.33 \mathrm{ug} / \mathrm{g}$. While the elimination of selenium dioxide proceeded in a consistently linear fashion, that of sodium selenite diminished after the second week, at which time the body burden of selenium was $7.68 \mathrm{ug} / \mathrm{g}$ (Figures 11 and 12 ). The body burden of selenium for selenium dioxide shows a consistent linear elimination to approximately $10 \mathrm{ug} / \mathrm{g}$. No data are available for selenium dioxide elimination below this value. It is not known whether elimination would have diminished after the body burden of selenium reached a minimum level. However, it is possible that, as with chromium, the residual selenium from either test agent may persist in the worms' tissues longer than implied by the half-life values. 
The considerations discussed above contribute to the conclusion that, while selenium dioxide was more toxic than sodium selenite to $E$. foetida, selenium was absorbed equally efficiently from either of these test agents, and potentially remained in the earthworm's tissues longer than can be predicted by the half-lives of elimination. 
Conclusion:

This study is the first to present a method for the quantification of delivered dose during contact exposure of earthworms. This diminishes the major disadvantage of using contact exposures to determine toxicity: the lack of quantification of administered dose. Quantification enables the investigator to study toxicologic parameters other than LC $_{50}$ toxicity. Chemical analysis of the specimens allows for the examination of absorption and elimination rates which provide more complete toxicology information.

The advantages of using contact exposures in the study of chemical toxicity to earthworms include making use of a natural exposure route and preservation of the natural defense of the worm's body wall. A worm's primary defense against xenobiotics and disease agents is the selective permeability of its body wall. The worm's body wall also functions in the distribution of absorbed components. Since this natural defense is preserved in contact exposures, a more realistic view of chemical-organism interactions can be gained. This is important in environmental risk assessment. Using this method of contact exposure in $E$. foetida combined with chemical analysis, the relative toxicities, absorption rates and elimination rates were compared for four test agents: chromium trioxide, chromium chloride, selenium dioxide and sodium selenite. Although chromium trioxide was found to be more toxic to this earthworm than 
chromium chloride, a comparison of chromium contents of the test solutions show that classification of toxicity of chromium did not differ by chemical form. The preferential uptake of chromium VI by the worm tissues at the cellular level could not be confirmed. The whole body absorption of the chromium compounds was affected by surface-reducing behaviors of the worm, tissue damage caused by the test agent, and the chemical form and concentration.

The toxicity of the selenium test agents in $E$. foetida depended primarily on the chemical form of the test agent. Selenium dioxide was more toxic than sodium selenite and the test agents were classified into separate toxicity classes regardless of whether one used the concentration of the whole test agent or the selenium content of the test agent. Selenium exposed worms did not demonstrate surface-reducing behavior nor did the selenium cause primary tissue damage. Additionally, combining the absorption assay data for the two selenium compounds showed that absorption of selenium depended primarily on the amount of selenium available and seemed to be little affected by chemical form.

Elimination of the two chromium compounds and sodium selenite proceeded in two discernible phases. In the first phase, the metals were eliminated at a constant rate. In the second phase the amount of metal remained fairly constant and little elimination occurred. Selenium dioxide was eliminated at a constant rate throughout the six weeks 
of the study and showed no tendency toward a second static phase. However, the body burden of selenium remaining at the end of six weeks was higher than the body burden of selenium at which elimination ceased for sodium selenite. It is possible that the selenium dioxide exposed worms did not reach the second phase of elimination during the six weeks of the study. Elimination of both chromium and selenium test agents followed zero order kinetics during phase I elimination: constant amounts of the metals were eliminated per unit time, independent of total body burden. However, for the chromium test agents and sodium selenite, once a minimum level of metal was reached, elimination decreased and the body burden of the metal remained relatively constant. This minimum metal level differed between the chromium test agents. $E$. foetida retained a higher level of chromium from chromium trioxide than from chromium chloride. No minimum retention level was observed for selenium dioxide, but it is possible that the minimum level was not reached in the six weeks of the assay. The elimination information has implications for the fate of chromium and selenium in the environment. Exposed earthworms may retain residual levels indefinitely, thus increasing the risk that chromium and selenium will be introduced to higher trophic levels.

Other studies may expand the toxicologic parameters that may be studied in earthworms. Analyses have shown that 
earthworms have metabolic enzymes similar to mammals, such as glutathione s-transferase and catalase. They are also capable of forming metallothiones. Distribution may not be a critical toxicologic parameter for earthworms. However, scanning electron microscopic chemical analysis could be useful in the detection and localization of metallic compounds in earthworm tissues. It could also be used to help determine whether worm tissues show preferential uptake of chromium VI at the cellular level. 
References :

1. Clark, T., K. Clark, S. Paterson and D. Mackay. 1988. Wildife monitoring, modeling, and fugacity. Environmental Science and Technology. 22:120-127.

2. Suter, G.W. and A.E. Rosen. 1988. Comparative toxicology for risk assessment of marine fishes and crustaceans. Environmental Science and Technology. 22:548555.

3. Kenaga, E.E. 1982. Predictability of chronic toxicity from acute toxicity of chemicals in fish and aquatic invertebrate. Environmental Toxicology and Chemistry. 1:347-358.

4. Jenner, H.A., J.P. Janssen-Mommen and J.H. Koeman. 1992. Effects of coal gasification slag as a substrate for the plant Cypertus esculentus and the worm Eisenia fetida. Ecotoxicology and Environmental Safety. 24:46-47.

5. Holden, C. 1993. Toxicologists watch as the worm turns. Science. $261: 1525$.

6. Roberts B. and H.W. Dorough. 1984. Relative toxicities of chemicals to the earthworm Eisenia foetida. Environmental Toxicology and Chemistry. 3:67-78.

7. Karnak, R.E. and J.L. Hamelink. 1982. A standardized method for determining the acute toxicity of chemicals to earthworms. Ecotoxicology and Environmental Safety. 6:216-222. 
8. Stringer, A. and M.A. Wright. 1976. The toxicity of benomyl and some related 2-substituted benzimidazoles to the earthworm Lumbricus terrestris. Pesticide Science. 7:459464 .

9. Furst, A., Y. Chien and P.K. Chien. 1993. Worms as a substitute for rodents in toxicology: acute toxicity of three nickel compounds. Toxicology Methods. 3:19-23.

10. Roberts, B.L. and H.W. Dorough. 1985. Hazards of chemicals to earthworms. Environmental Toxicology and Chemistry. 4:307-323.

11. Beyer, W.N. and C.D. Gish. 1980. Persistence in earthworms and potential hazards to birds of soil applied DDT, dieldrin and heptachlor. Journal of Applied Ecology. $17: 295-307$

12. Ireland, M.P. 1975. The effect of the earthworm Dendrobaena rubida on the solubility of lead, zinc, and calcium, in heavy metal contaminated soil in Wales. Journal of soil science. $26: 313-318$.

13. Ash, C.P.J. and D.I. Lee. 1980. Lead, cadmium, copper and iron in earthworms from roadside sites. Environmental Pollution. 22:59-67.

14. Edwards, C.A. and J.R. Lofty. 1972. Biology of Earthworms. Chapman and Hall LTD, London. 
15. Bryan, G.W. and L.G. Hummerstone. 1971. Adaptation of the polychaete Nereis diversicolor to estuarine sediments containing high concentrations of heavy metals. Journal of Marine Biology Association U.K.. 51:845-863.

16. Heimbach, F. 1985. Comparison of laboratory methods using Eisenia foetida and Lumbricus terrestris, for the assessment of the hazard of chemicals to earthworms. Journal of Plant Disease and Protection. 92:186-193.

17. Anton, F.A., E. Laborda, P. Laborda and E. Ramos. 1993. Carbofuran acute toxicity to Eisenia foetida Savigny. Earthworms. Bulletin of Environmental Contamination and Toxicology. 50:407-12.

18. Diehl, W.J. and D.L. Williams. 1992. Distribution of polymorphisms among pathways of carbohydrate metabolism in the earthworm Eisenia fetida (Oligochaeta). Comparative Biochemistry and Physiology. 101:83-90.

19. Anton, F., E. Laborda and P. Laborda. 1990. Acute toxicity of the fungicide captan to the earthworm Eisenia foetida. Bulletin of Environmental Contamination and Toxicology. $45: 82-7$.

20. Van Leemput, L., E. Swysen, R. Woestenborghs, L. Michielsen, W. Meuldermans and J. Heykants. 1989. On the terrestrial toxicity of the fungicide imazalil (enilconazole) to the earthworms species Eisenia foetida. Ecotoxicology and Environmental Safety. 18:313-20. 
21. van Gestel, C.A., W.A. van Dis, E.M. van Breeman and P.M Sparenburg. 1989. Development of a standardized reproduction toxicity test with the earthworm species Eisenia fetida Andrei using copper, pentachlorophenol and 2,4-dichloroaniline. Ecotoxicology and Environmental Safety. $18: 305-12$.

22. National Research Council, National Academy of Sciences (NAS). 1980. Recommended Daily Allowances, 9 th ed. Washington, D.C.: NAS.

23. Katz, S.A. and H. Salem. 1993. The toxicology of chromium with respect to its chemical speciation: a review. Journal of Applied Toxicology. 13:217-24.

24. Mertz, พ. 1993. Chromium in human nutrition: a review. Journal of Nutrition. 123:626-33.

25. Anderson, R.A. 1993. Recent advances in the clinical and biochemical effects of chromium deficiency. Progress in Clinical and Biological Research. 380:221-34.

26. Anderson, R.A. 1989. Essentiality of chromium in humans. Science of the Total Environment. 86:75-81.

27. Morris, B.W., T.A. Gray and S. Macneil.1993. Glucose-dependent uptake of chromium in human and rat insulin-sensitive tissues. Clinical science. 84:477-82.

28. Rumpulainen, J.T. 1992. Chromium content of foods and diets. Biological Trace Element Research. 32:9-18. 
29. Gao, M., S.P. Binks, J.K. Chipman and I.S. Levy.1993. Hexavalent chromium produces DNA strand breakage but not unscheduled DNA synthesis at sub-cytoxic concentrations in hepatocytes. Toxicology. 77:171-80.

30. Sugiyama, M. 1992. Role of physiological antioxidants in chromium (VI)-induced cellular injury. Free Radical Biology and Medicine. 12:397-407.

31. De Flora, S., M. Bagnasco, D. Serra and P. Zanacchi. 1990. Genotoxicity of chromium compounds. A review. Mutation Research. 238:99-172.

32. Wetterhann, K.E. and J.W. Hamilton. 1989. Molecular basis of hexavalent chromium carcinogenicity: effect on gene expression. Science of the Total Environment. 86:113-29.

33. Paustenbach, D.J., P.J. Sheehan, J.M. Paull, L.M. wisser, B.L. Finley. 1992. Review of the allergic contact dermatitis hazard posed by chromium-contaminated soil: identifying a "safe" concentration. Journal of Toxicology and Environmental Health. 37:177-207.

34. Outridge, R.M. and A.M. Scheuhammer. 1993. Bioaccumulation and toxicology of chromium: implications for wildlife. Review of Environmental Contamination and Toxicology. $130: 31-77$.

35. Neve, J. 1991. Physiological and nutritional importance of selenium. Experientia. 47:187-93. 
36. Levander, 0.A. 1991. Scientific rationale for the 1989 recommended dietary allowance for selenium. Journal of the American Dietetic Association. 91:1572-6.

37. Zachara, B.A. 1992. Mammalian selenoproteins. Journal of Trace Elements and Electrolytes in Health and Disease. $6: 137-51$.

38. Olsson, U., B. Lundgren, J. Segura-Aguilar, A. Messing-Eriksson, K. Andersson, L. Becedas and J.W. De Pierre. 1993. Effects of selenium deficiency on xenobioticmetabolizing and other enzymes in rat liver. International Journal for Vitamin and Nutrition Research. 63:31-7.

39. Dorgan, J.F. and A Schatzkin.1991. Antioxidant micronutrients in cancer prevention. Hematology-oncology Clinics of North America. 5:43-68.

40. Ip, C., C. Hayes, R.M. Budnick and H.E. Ganther. 1991. Chemical form of selenium, critical metabolites and cancer prevention. Cancer Research. 52:595-600.

41. Arthur, J.R., F. Nicol, G.J. Beckett.1992. The role of selenium in thyroid hormone metabolism and effects of selenium deficiency on thyroid hormone and iodine metabolism. Biological Trace Element Research. 34:321-5.

42. Presser, T.S. and I. Barnes. 1984. Selenium concentrations in water tributary to and in the vicinity of the Kesterson National Wildlife Refuge, Fresno and Merced Counties, California. Water Resources Investigation Report 84-4122. U.S. Geologic Survey, Menlo Park, CA. (26) 
43. Ge, K. and G. Yang. 1993. The epidemiology of selenium deficiency in the etiological study of endemic diseases in China. American Journal of Clinical Nutrition. $57: 259 S-263 S$.

44. Edmondson, A.J., B.B. Norman and D. Suther. 1993. Special Report: Survey of state veterinarians and state veterinary diagnostic laboratories for selenium deficiency and toxicosis in animals. Jounal of the American Veterinary Medicine Association. 202:865-72.

45. Presser, T.S., H.C. Swain, R.R. Tidball and R.C. Severson. 1990. Geologic sources, mobilization and transport of the Western San Joaquin Valley: a reconnaissance study. Water Resources Investigation Report 90-4070. U.S. Geologic Survey, Menlo Park, CA. (66)

46. Presser, T.S. and H.M. Ohlendorf. 1987. Biogeochemical cycling of selenium in the San Joaquin Valley, California, USA. Environmental Management. 11:805821.

47. Diplock, A.T. 1993. Indexes of selenium status in human populations. American Journal of Clinical Nutrition Supplement. $57: 2565-258$ S .

48. Renwick, A.G. 1989. Pharmacokinetics in toxicology. In A.W. Hayes, ed., Principles and Methods of Toxicology, 2nd ed. ,Raven Press Ltd., New York, NY. 


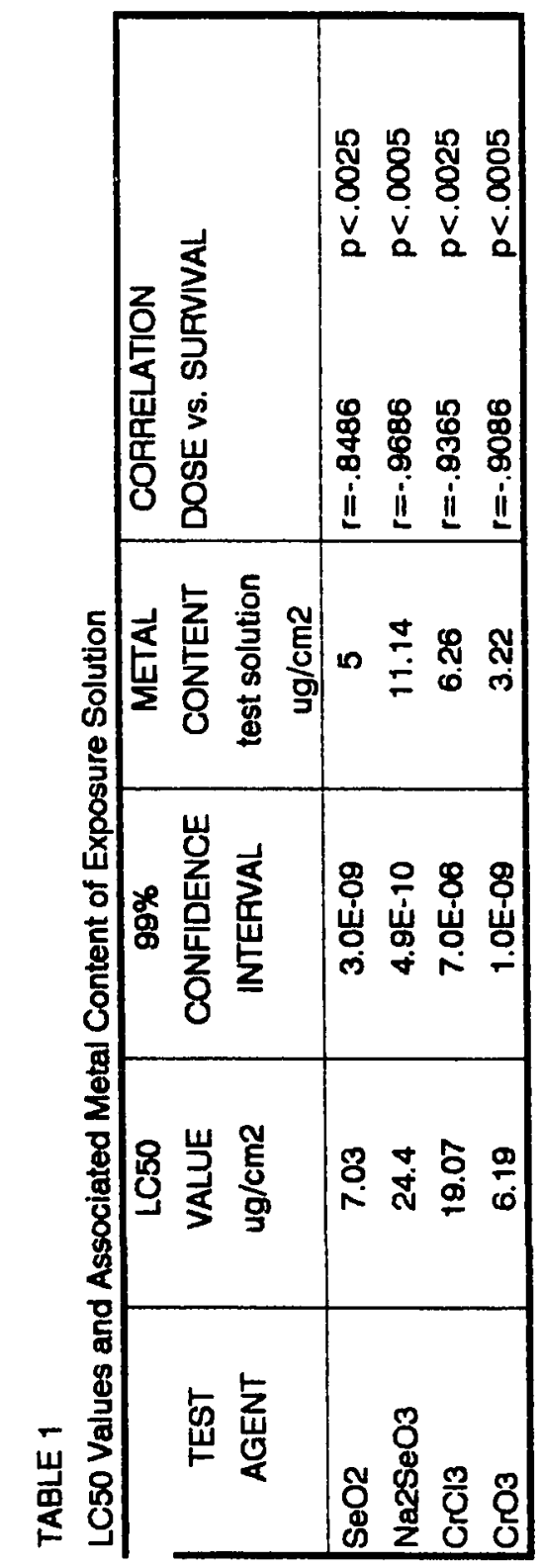




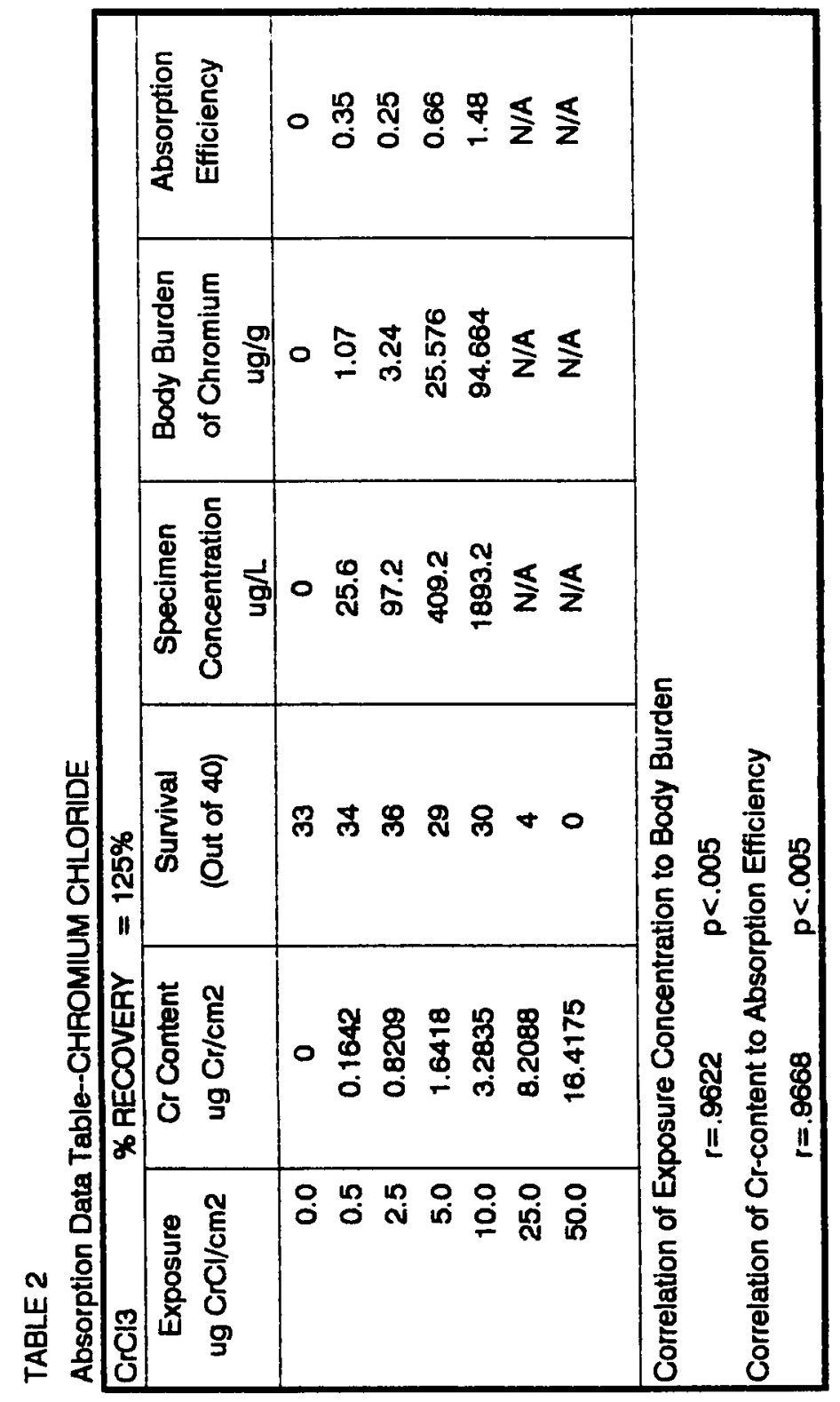




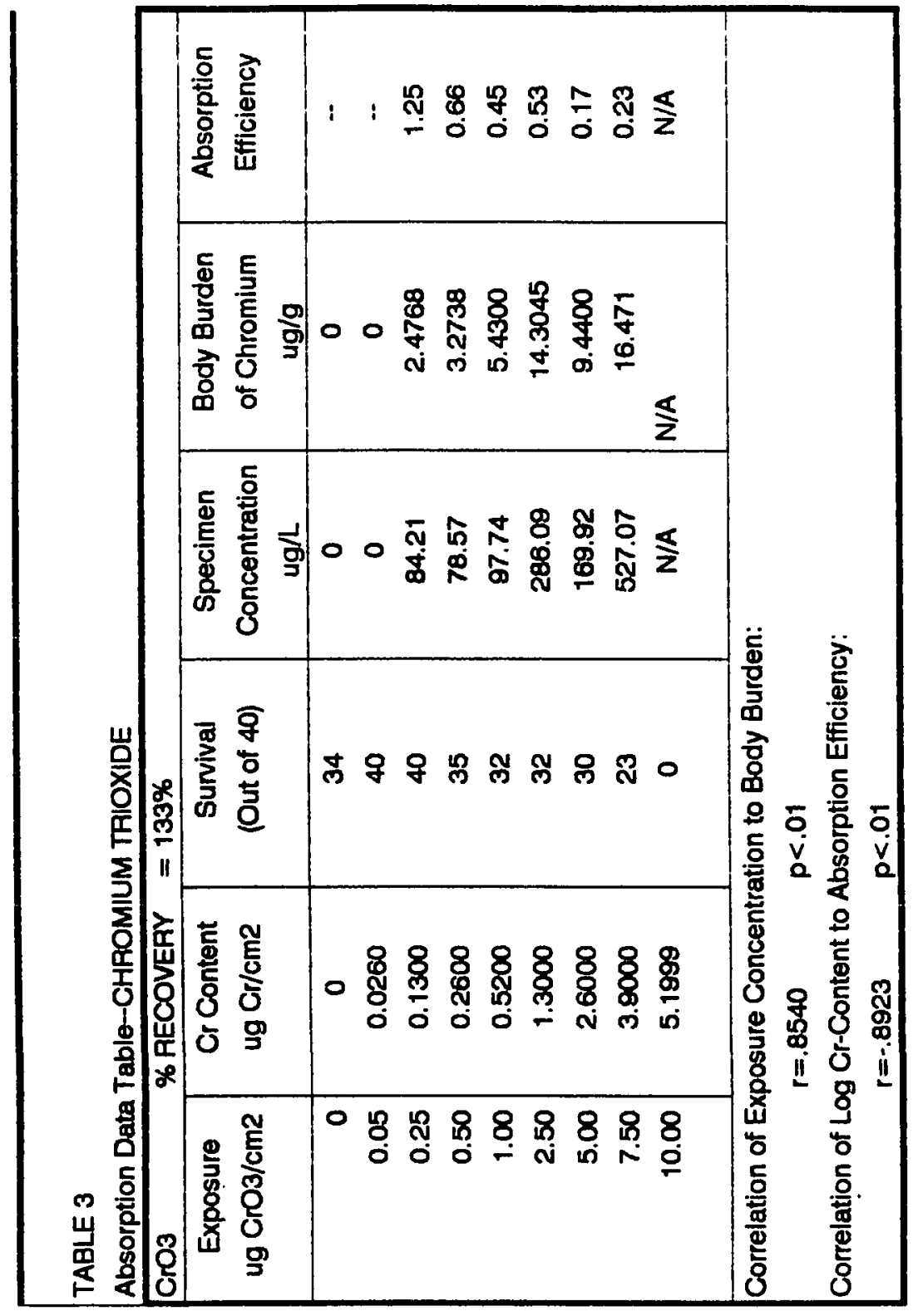




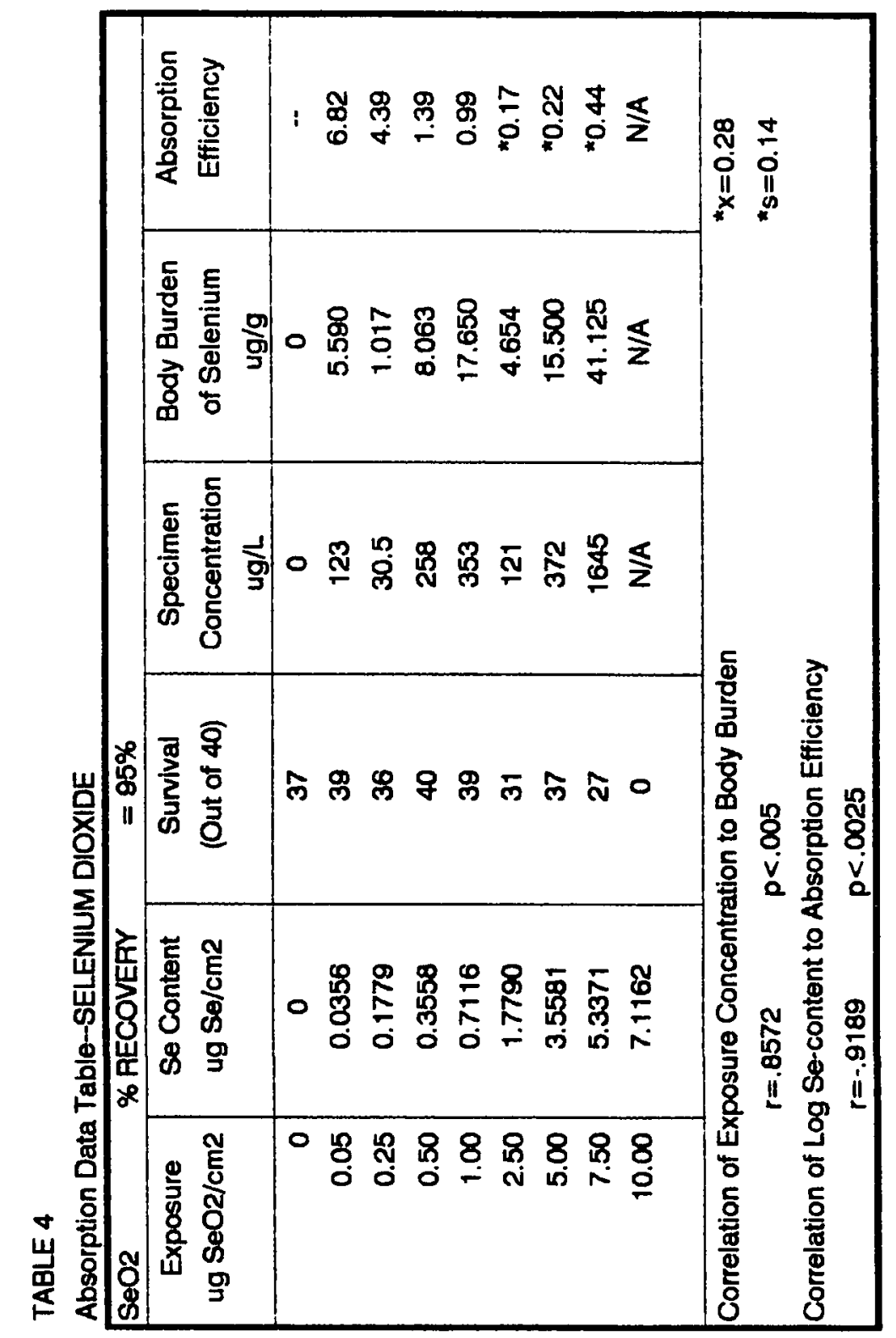




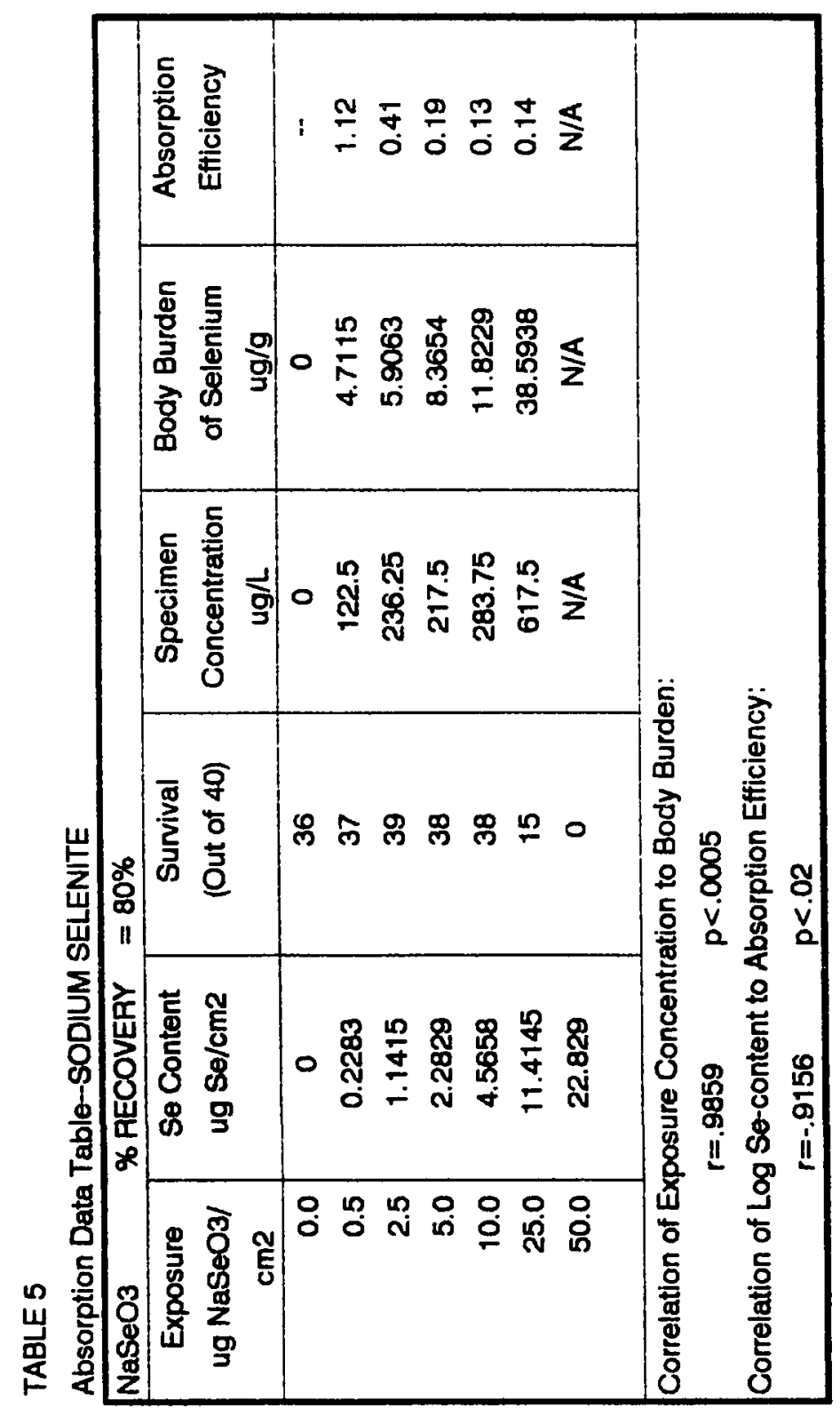




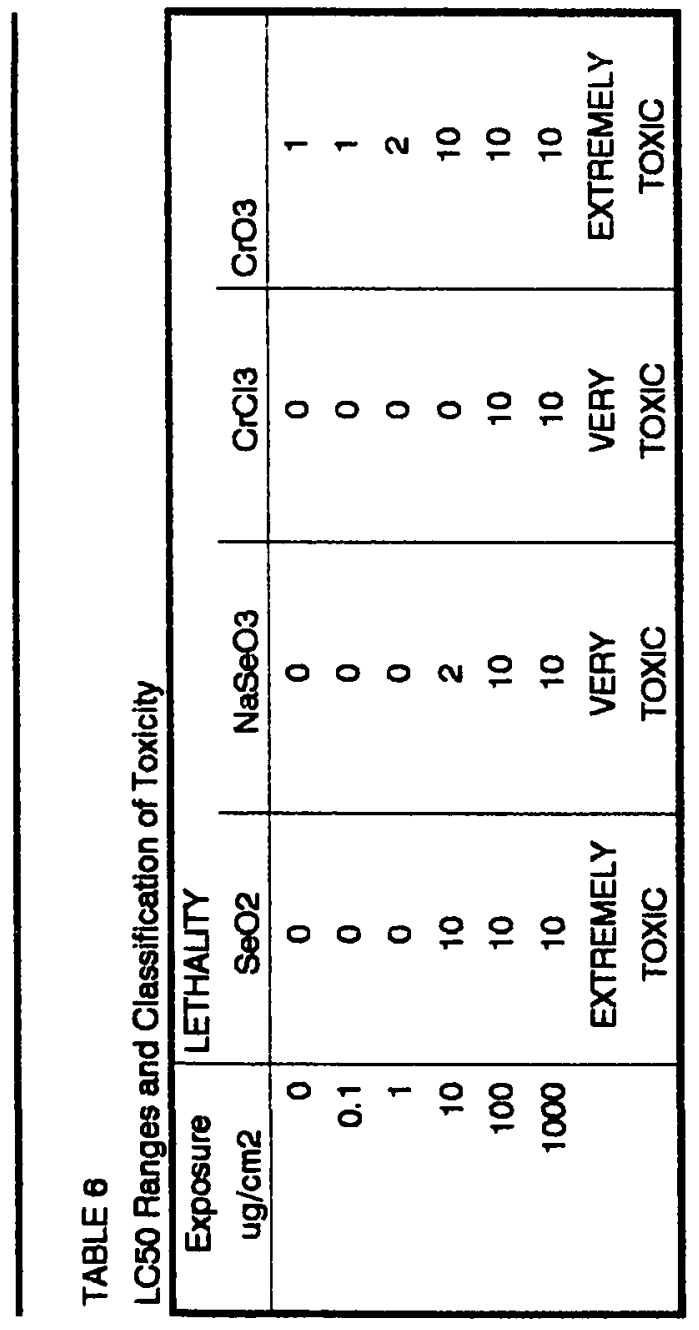


TABLE 7A

\begin{tabular}{|c|c|c|c|}
\hline \multicolumn{4}{|c|}{$\begin{array}{l}\text { COMPARATIVE WEIGHT TABLE--CHRON } \\
\text { Absorption Assay Weights }\end{array}$} \\
\hline $\begin{array}{c}\text { CrCl3 } \\
\text { Exposure } \\
\text { Concentration }\end{array}$ & $\begin{array}{c}\text { Average } \\
\text { Pre-TX } \\
\text { Weight }\end{array}$ & $\begin{array}{l}\text { Average } \\
\text { Post-TX } \\
\text { Weight }\end{array}$ & $\begin{array}{c}\text { Weight } \\
\text { Ratio } \\
\text { PRE:POST }\end{array}$ \\
\hline 0.0 & 0.2300 & 0.2303 & 0.9987 \\
\hline 0.5 & 0.2200 & 0.2294 & 0.9590 \\
\hline 2.5 & 0.2625 & 0.2417 & 1.0861 \\
\hline 5.0 & 0.2000 & 0.1828 & 1.0941 \\
\hline \multirow[t]{4}{*}{10.0} & 0.2250 & 0.1733 & 1.2983 \\
\hline & $x=.2275$ & $x=.2115$ & $x=1.0872$ \\
\hline & $s=.0226$ & $s=.0312$ & $s=.1312$ \\
\hline & & & $p>0.25$ \\
\hline
\end{tabular}

TABLE 7B

\begin{tabular}{|c|c|c|c|}
\hline \multicolumn{4}{|c|}{$\begin{array}{l}\text { COMPARATIVE WEIGHT TABLE-CHROMIUM TRIOXIDE } \\
\text { Absorption Assay Weights }\end{array}$} \\
\hline $\begin{array}{c}\text { CrO3 } \\
\text { Exposure } \\
\text { Concentration }\end{array}$ & $\begin{array}{c}\text { Average } \\
\text { Pre-TX } \\
\text { Weight }\end{array}$ & $\begin{array}{l}\text { Average } \\
\text { Post-TX } \\
\text { Weight }\end{array}$ & $\begin{array}{c}\text { Weight } \\
\text { Ratio } \\
\text { PRE:POST } \\
\end{array}$ \\
\hline 0.0 & 0.2100 & 0.2206 & 0.9519 \\
\hline 0.05 & 0.2925 & 0.2675 & 1.0935 \\
\hline 0.25 & 0.2475 & 0.2425 & 1.0206 \\
\hline 0.5 & 0.1875 & 0.1800 & 1.0417 \\
\hline 1.0 & 0.1875 & 0.1938 & 0.9675 \\
\hline 2.5 & 0.2275 & 0.2031 & 1.1201 \\
\hline 5.0 & 0.1769 & 0.1500 & 1.1793 \\
\hline \multirow[t]{4}{*}{7.5} & 0.2200 & 0.1826 & 1.2048 \\
\hline & $x=.2187$ & $x=.2050$ & $x=1.0724$ \\
\hline & $s=.0380$ & $s=.0342$ & $s=.0932$ \\
\hline & & & $p>.20$ \\
\hline
\end{tabular}


TABLE 7C

COMPARATIVE WEIGHT TABLE--SODIUM SELENITE Absorption Assay Weights

\begin{tabular}{|r|c|c|c|}
\hline $\begin{array}{c}\text { NaSe03 } \\
\text { Exposure } \\
\text { Concentration }\end{array}$ & $\begin{array}{c}\text { Average } \\
\text { Pre-TX } \\
\text { Weight }\end{array}$ & $\begin{array}{c}\text { Average } \\
\text { Post-TX } \\
\text { Weight }\end{array}$ & $\begin{array}{c}\text { Weight } \\
\text { Ratio } \\
\text { PRE:POST }\end{array}$ \\
\hline 0.0 & 0.2800 & 0.2333 & 1.2002 \\
0.5 & 0.2625 & 0.2243 & 1.1703 \\
2.5 & 0.2950 & 0.2128 & 1.3863 \\
5.0 & 0.2975 & 0.2105 & 1.4133 \\
10.0 & 0.2250 & 0.2000 & 1.1250 \\
25.0 & 0.2000 & 0.1867 & 1.0712 \\
\hline & $x=.2600$ & $x=.2113$ & $x=1.2277$ \\
& $s=.0418$ & $s=.0167$ & $s=.1405$ \\
& & & $P>.20$ \\
\hline
\end{tabular}

TABLE 7D

\begin{tabular}{|c|c|c|c|}
\hline \multicolumn{4}{|c|}{$\begin{array}{l}\text { COMPARATIVE WEIGHT TAE } \\
\text { Absorption Assay Weights }\end{array}$} \\
\hline $\begin{array}{c}\mathrm{SeO} 2 \\
\text { Exposure } \\
\text { Concentration }\end{array}$ & $\begin{array}{c}\text { Average } \\
\text { Pre-TX } \\
\text { Weight }\end{array}$ & $\begin{array}{l}\text { Average } \\
\text { Post-TX } \\
\text { Weight }\end{array}$ & $\begin{array}{c}\text { Weight } \\
\text { Ratio } \\
\text { PRE:POST }\end{array}$ \\
\hline 0.0 & 0.2100 & 0.2622 & 0.8009 \\
\hline 0.05 & 0.2475 & 0.2308 & 1.0724 \\
\hline 0.25 & 0.2400 & 0.1944 & 1.2346 \\
\hline 0.5 & 0.2575 & 0.2350 & 1.0957 \\
\hline 1.0 & 0.2850 & 0.2590 & 1.1004 \\
\hline 2.5 & 0.2500 & 0.2258 & 1.1072 \\
\hline 5.0 & 0.2375 & 0.2027 & 1.1717 \\
\hline \multirow[t]{4}{*}{7.5} & 0.2400 & 0.1926 & 1.2461 \\
\hline & $x=.2459$ & $x=.2253$ & $x=1.1036$ \\
\hline & $\mathrm{s}=.0211$ & $s=.0271$ & $s=.1388$ \\
\hline & & & $P>.15$ \\
\hline
\end{tabular}


TABLE 8

Elimination Data Table--CHROMIUM TEST AGENTS

\begin{tabular}{|c|c|c|c|c|c|}
\hline \multicolumn{3}{|c|}{ CrCl Elimination Assay } & \multicolumn{3}{|c|}{ Cro3 Elimination Assay } \\
\hline $\begin{array}{l}\text { TIME } \\
\text { Post-Expo } \\
\text { Days }\end{array}$ & $\begin{array}{l}\text { BODY } \\
\text { BURDEN } \\
\text { ug/g }\end{array}$ & $\begin{array}{l}\text { Ln of } \\
\text { BODY } \\
\text { BURDEN }\end{array}$ & $\begin{array}{l}\text { TIME } \\
\text { Post-Expo } \\
\text { Days }\end{array}$ & $\begin{array}{l}\text { BODY } \\
\text { BURDEN } \\
\text { ug/g }\end{array}$ & $\begin{array}{l}\text { Ln of } \\
\text { BODY } \\
\text { BURDEN }\end{array}$ \\
\hline 3 & 21.0571 & 3.0472 & 0 & 20.6532 & 3.0279 \\
\hline 4 & 17.5636 & 2.8658 & 0.5 & 18.3198 & 2.9080 \\
\hline 5 & 9.9040 & 2.2929 & 1 & 17.1429 & 2.8416 \\
\hline 6 & 9.7333 & 2.2756 & 2 & 17.8571 & 2.8824 \\
\hline 7 & 10.3556 & 2.3375 & 5 & 16.7293 & 2.8172 \\
\hline 14 & 5.4800 & 1.7011 & 7 & 14.4737 & 2.6723 \\
\hline 21 & 7.0000 & 1.9459 & 14 & 10.2796 & 2.3302 \\
\hline 28 & 6.8000 & 1.9169 & 22 & 10.2646 & 2.3287 \\
\hline 35 & 7.2000 & 1.9741 & 28 & 12.4165 & 2.5190 \\
\hline 42 & 6.0533 & 1.8006 & 35 & 11.6810 & 2.4580 \\
\hline \multicolumn{3}{|c|}{$\begin{array}{l}\text { Phase I Elimination: } \\
\text { Days } 3 \text { through } 14 \\
\text { Correlation of Time } \\
\text { to Ln of Body Burden }\end{array}$} & \multicolumn{3}{|c|}{$\begin{array}{l}\text { Phase I Elimination: } \\
\text { Days } 0 \text { through } 14 \\
\text { Correlation of Time } \\
\text { to Ln of Body Burden }\end{array}$} \\
\hline $\begin{array}{l}r=-.8973 \\
C o=22.9 \\
C 1 / 2=11 \\
t 1 / 2=6.38 \\
k=0.1094\end{array}$ & $\begin{array}{l}=4.065 \\
\lg / \mathrm{g} \\
4 \mathrm{ug} / \mathrm{g} \\
\text { days }\end{array}$ & $p<.01$ & $\begin{array}{l}r=-.9714 \\
C o=19.44 \\
c 1 / 2=9.7 \\
t 1 / 215.82 \\
k=0.0438\end{array}$ & $\begin{array}{l}=9.148 \\
\mathrm{ug} / \mathrm{g} \\
\mathrm{ug} / \mathrm{g} \\
\text { ays }\end{array}$ & $p<.0005$ \\
\hline \multicolumn{3}{|c|}{$\begin{array}{l}\text { Phase II Elimination: } \\
\qquad \begin{array}{l}\text { Days } 14 \text { through } 42 \\
n=5 \\
x=6.51 \mathrm{ug} / \mathrm{g} \\
\mathrm{s}=.7193\end{array}\end{array}$} & \multicolumn{3}{|c|}{$\begin{array}{l}\text { Phase II Elimination } \\
\qquad \begin{array}{l}n=4 \\
x=11.16 \mathrm{ug} / \mathrm{g} \\
\mathrm{x}=1.0688\end{array}\end{array}$} \\
\hline
\end{tabular}


TABLE 9

Elimination Data Table--SELENIUM TEST AGENTS

\begin{tabular}{|c|c|c|c|c|c|}
\hline \multicolumn{3}{|c|}{ SeO2 Elimination Assay } & \multicolumn{3}{|c|}{ NaSeO3 Elimination Assay } \\
\hline $\begin{array}{l}\text { TIME } \\
\text { POST-EX } \\
\text { Days }\end{array}$ & $\begin{array}{l}\text { BODY } \\
\text { BURDEN } \\
\text { ug/g }\end{array}$ & $\begin{array}{l}\text { Ln of } \\
\text { BODY } \\
\text { BURDEN }\end{array}$ & $\begin{array}{l}\text { TIME } \\
\text { POST-EX } \\
\text { Days }\end{array}$ & $\begin{array}{l}\text { BODY } \\
\text { BURDEN } \\
\text { ug/g }\end{array}$ & $\begin{array}{l}\text { Ln of } \\
\text { BODY } \\
\text { BURDEN }\end{array}$ \\
\hline 1 & 32.4377 & 3.4793 & 2 & 23.1978 & 3.1441 \\
\hline 4 & 28.5789 & 3.3527 & 3 & 23.2188 & 3.1450 \\
\hline 5 & 26.5928 & 3.2806 & 4 & 19.0789 & 2.9486 \\
\hline 6 & 25.8421 & 3.2520 & 5 & 18.125 & 2.8973 \\
\hline 7 & 24.2807 & 3.1897 & 6 & 16.6071 & 2.8098 \\
\hline 21 & 24.0977 & 3.1821 & 7 & 14.5395 & 2.6769 \\
\hline 28 & 24.2105 & 3.1868 & 14 & 7.7083 & 2.0423 \\
\hline 35 & 13.3684 & 2.5929 & 21 & 6.7708 & 1.9126 \\
\hline 42 & 15.4017 & 2.7345 & 31 & 8.6808 & 2.1611 \\
\hline & & & 45 & 7.2426 & 1.9800 \\
\hline \multicolumn{3}{|c|}{$\begin{array}{l}\text { Phase I Elimination: } \\
\text { Days } 1 \text { through } 42 \\
\text { Correlation of Time } \\
\text { to Ln of Body Burden }\end{array}$} & \multicolumn{3}{|c|}{$\begin{array}{l}\text { Phase I Elimination: } \\
\text { Days } 2 \text { through } 14 \\
\text { Correlation of Time } \\
\text { to Ln of Body Burden }\end{array}$} \\
\hline \multirow[t]{2}{*}{$\begin{array}{l}r=-.8771 \\
C o=30.3 \\
C 1 / 2=15 \\
t 1 / 2=42.0 \\
k=0.0165\end{array}$} & $\begin{array}{l}=4.831 \\
\mathrm{ug} / \mathrm{g} \\
64 \mathrm{ug} / \mathrm{g} \\
\text { days }\end{array}$ & $p<.001$ & $\begin{array}{l}r=-.9957 \\
c o=28.9 \\
c 1 / 2=14 \\
t 1 / 2=7.3 \\
k=0.0946\end{array}$ & $\begin{array}{l}=24.034 \\
\mathrm{ug} / \mathrm{g} \\
5 \mathrm{ug} / \mathrm{g} \\
\text { days }\end{array}$ & $p<.0005$ \\
\hline & & & \multicolumn{3}{|c|}{$\begin{array}{l}\text { Phase II Elimination: } \\
\qquad \begin{array}{l}n=4 \\
x=7.60 \mathrm{ug} / \mathrm{g} \\
\mathrm{s}=.8155\end{array}\end{array}$} \\
\hline
\end{tabular}




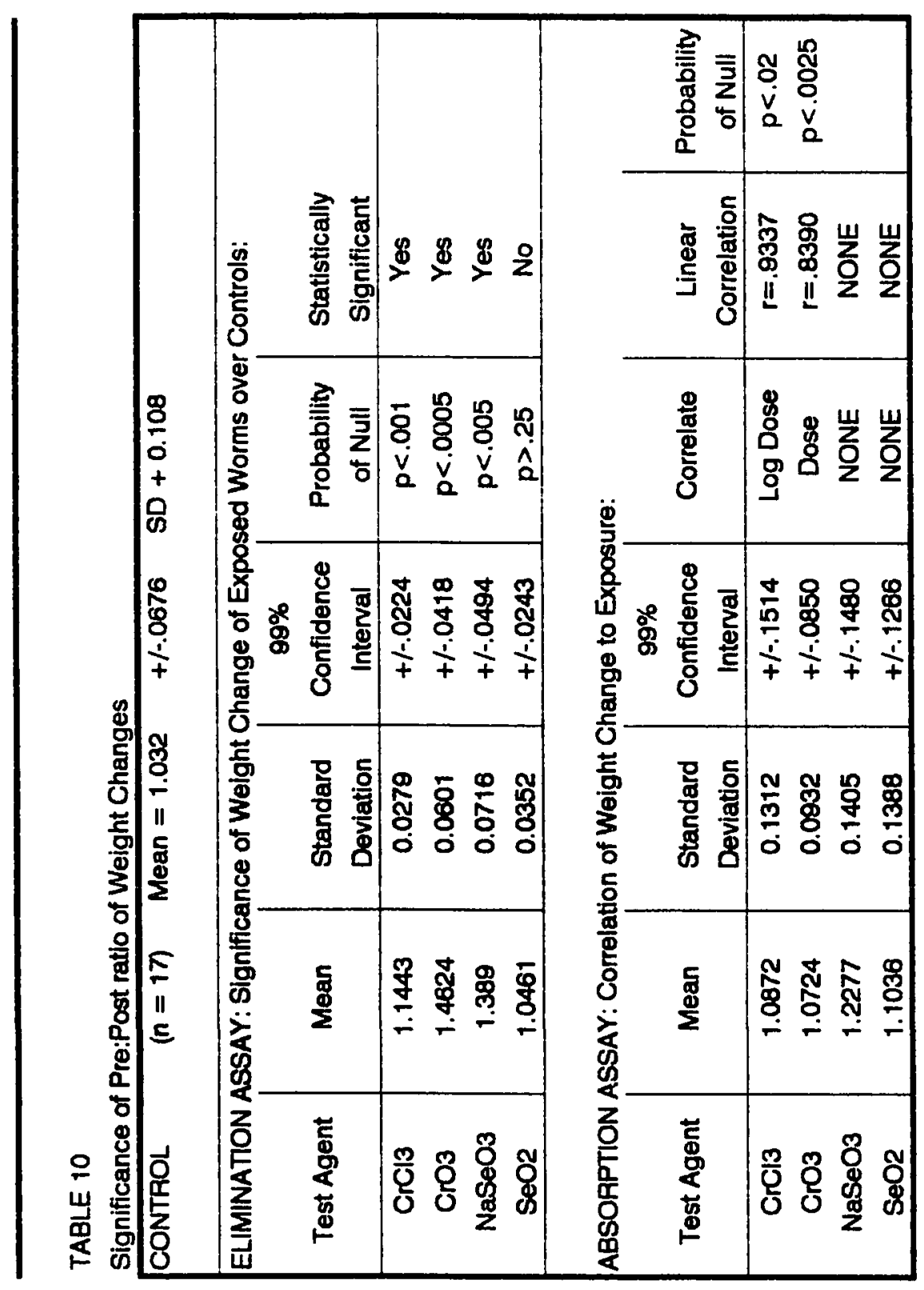


TABLE 11

Combined Correlation of Selenium Content

of the Test Solution to the Absorption Efficiency

\begin{tabular}{|c|c|c|c|}
\hline $\begin{array}{c}\text { TEST } \\
\text { AGENT }\end{array}$ & $\begin{array}{l}\text { SELENIUM } \\
\text { CONTENT O } \\
\text { SOLUTION }\end{array}$ & $\begin{array}{l}\text { LOG } \\
\text { SELENIUM } \\
\text { CONTENT }\end{array}$ & $\begin{array}{l}\text { ABSORPTION } \\
\text { EFFICIENCY }\end{array}$ \\
\hline & 0 & & -- \\
\hline $\mathrm{SeO} 2$ & 0.0356 & -1.4486 & 6.82 \\
\hline $\mathrm{SeO} 2$ & 0.1779 & -0.7498 & 4.39 \\
\hline $\mathrm{Na2SeO}$ & 0.2283 & -0.6415 & 1.12 \\
\hline $\mathrm{SeO} 2$ & 0.3558 & -0.4488 & 1.39 \\
\hline $\mathrm{SeO} 2$ & 0.7716 & -0.1126 & 0.99 \\
\hline $\mathrm{Na2SeO} 3$ & 1.1415 & 0.0575 & 0.41 \\
\hline $\mathrm{SeO} 2$ & 1.779 & 0.2502 & 0.17 \\
\hline $\mathrm{Na2SeO} 3$ & 2.2829 & 0.3585 & 0.19 \\
\hline $\mathrm{SeO} 2$ & 3.5581 & 0.5512 & 0.22 \\
\hline $\mathrm{Na2SeO} 3$ & 4.5658 & 0.6595 & 0.13 \\
\hline $\mathrm{S} 0 \mathrm{O} 2$ & 5.3371 & 0.7273 & 0.44 \\
\hline $\mathrm{Na2SeO} 3$ & 11.4145 & 1.0575 & 0.14 \\
\hline \multicolumn{4}{|c|}{$\begin{array}{l}\text { Correlation of Log Se-Content to Absorption Efficiency } \\
\qquad r=-.8439 \quad p<.0005\end{array}$} \\
\hline
\end{tabular}




\section{Weight Loss During Exposure CHROMIUM CHLORIDE}

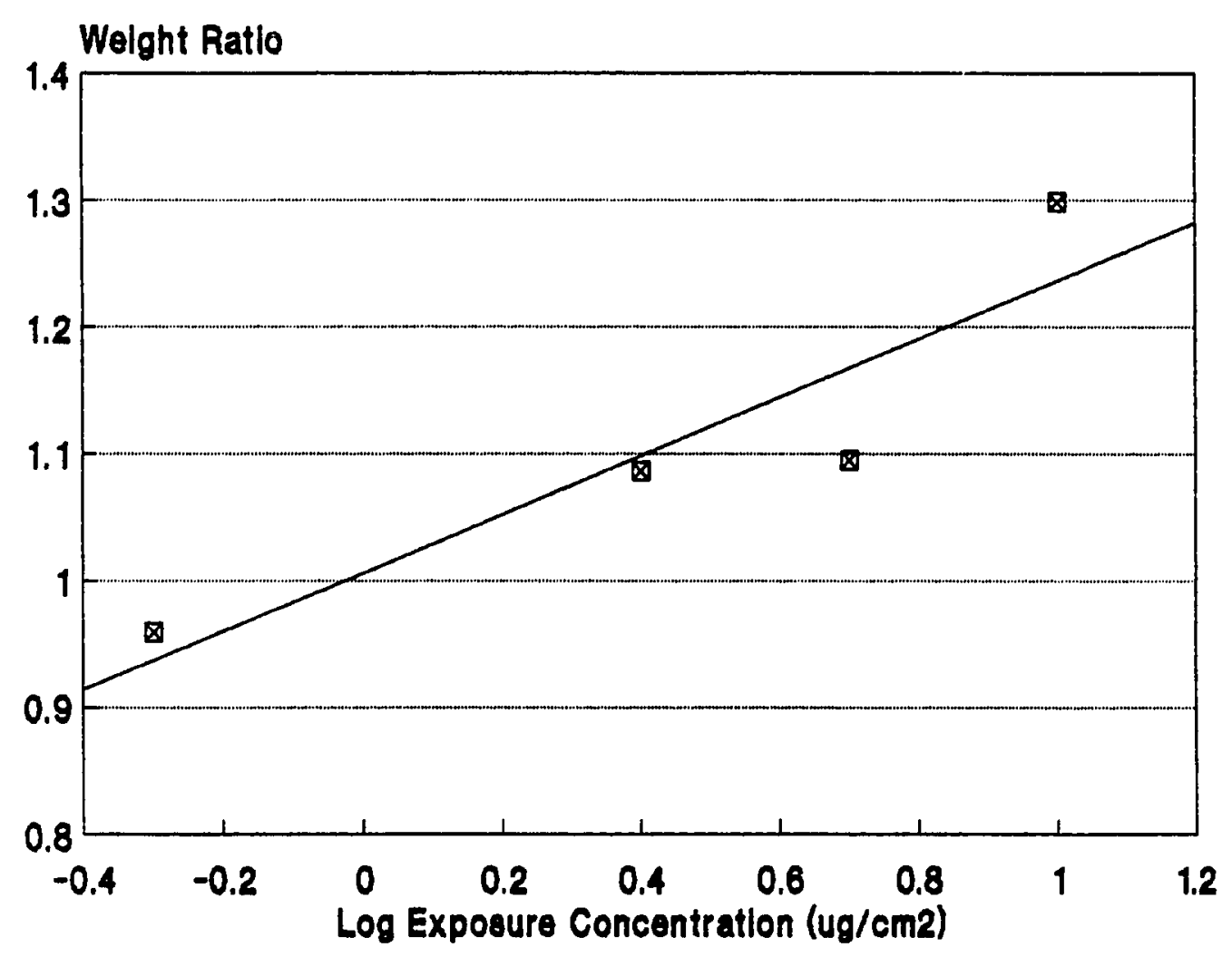

FIGURE 1 


\section{Weight Loss During Exposure CHROMIUM TRIOXIDE}

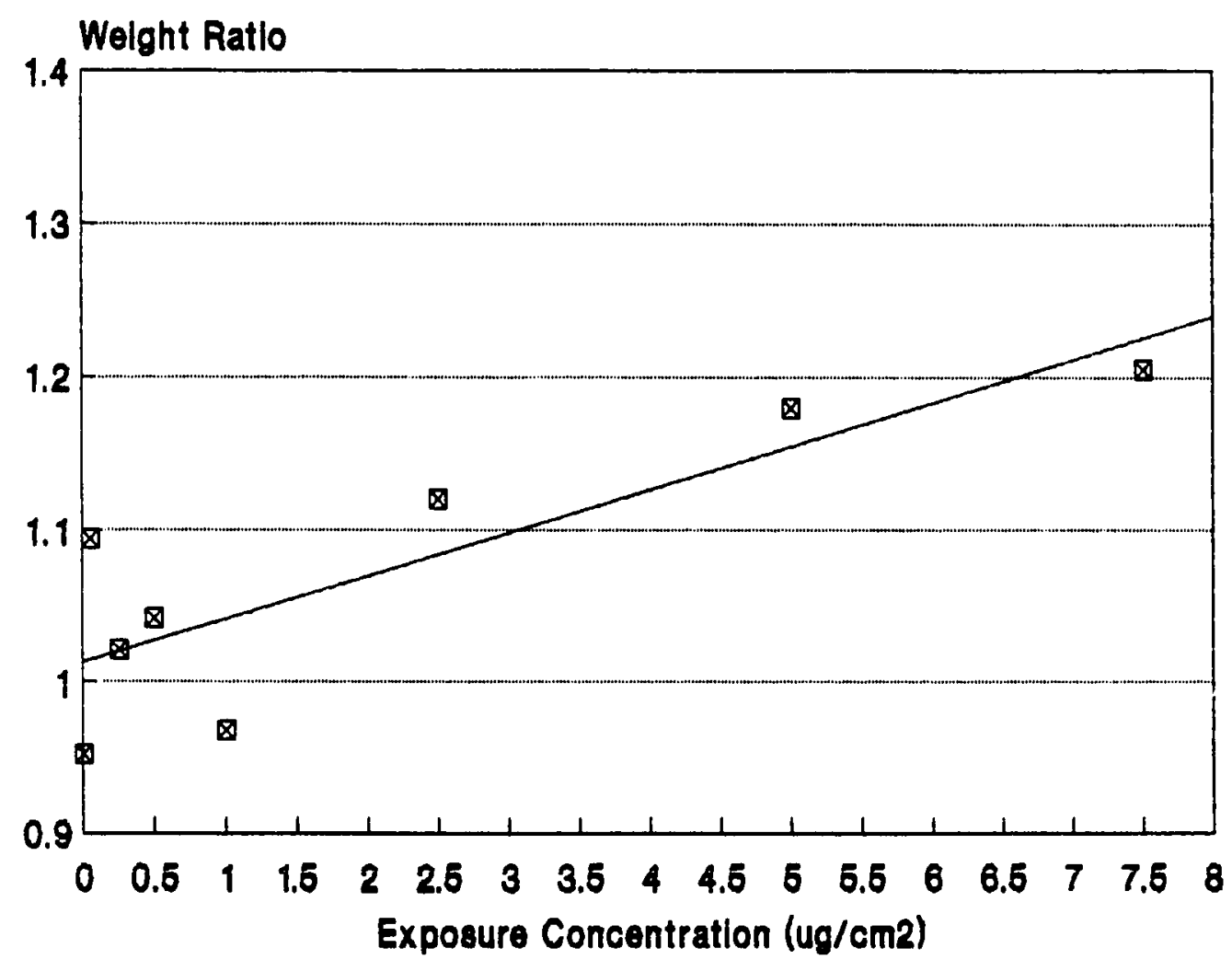

FIGURE 2 


\section{Weight Loss During Exposure SODIUM SELENITE}

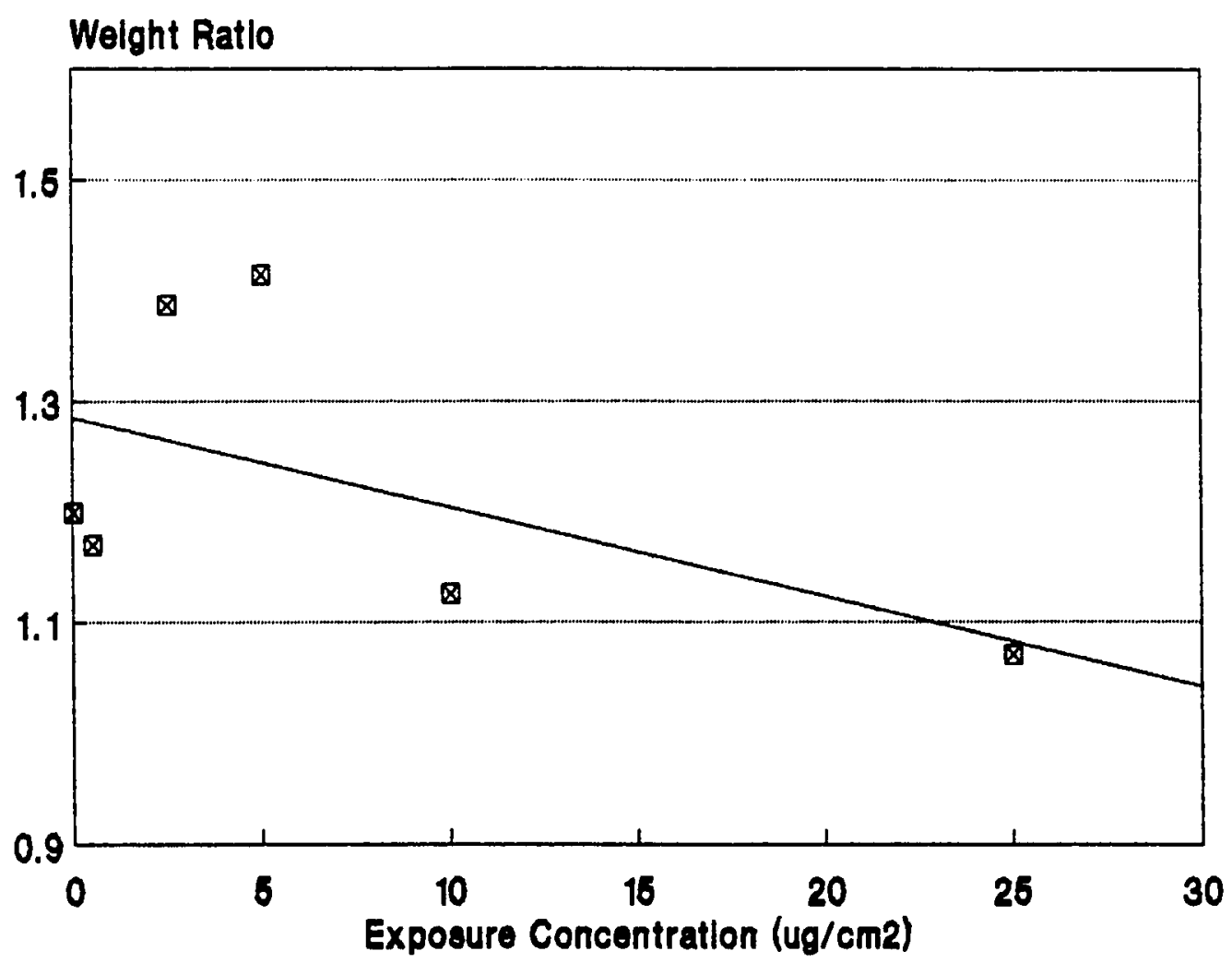

FIGURE 3 


\section{Weight Loss During Exposure SELENIUM DIOXIDE}

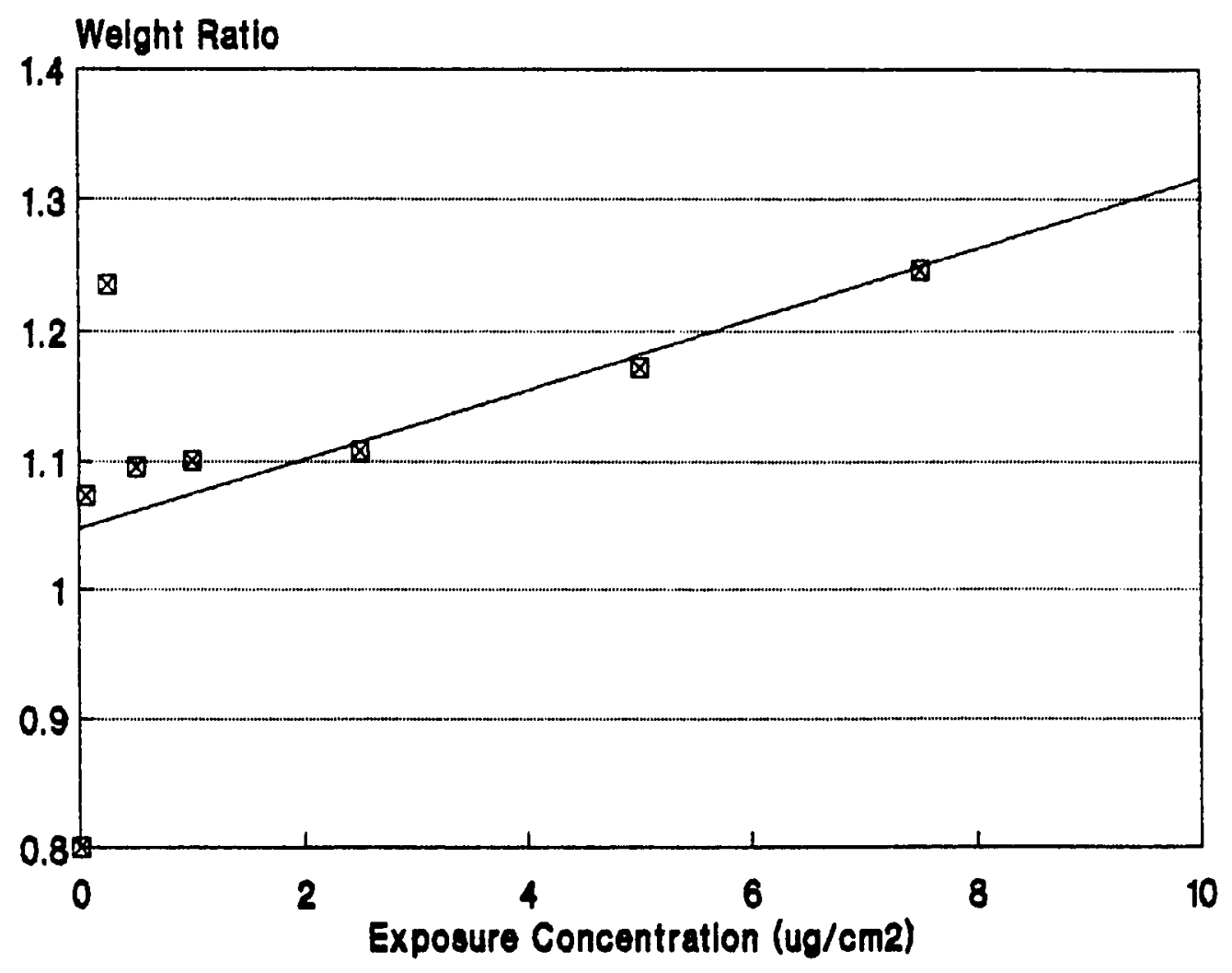

FIGURE 4 
CHROMIUM CHLORIDE

LC50

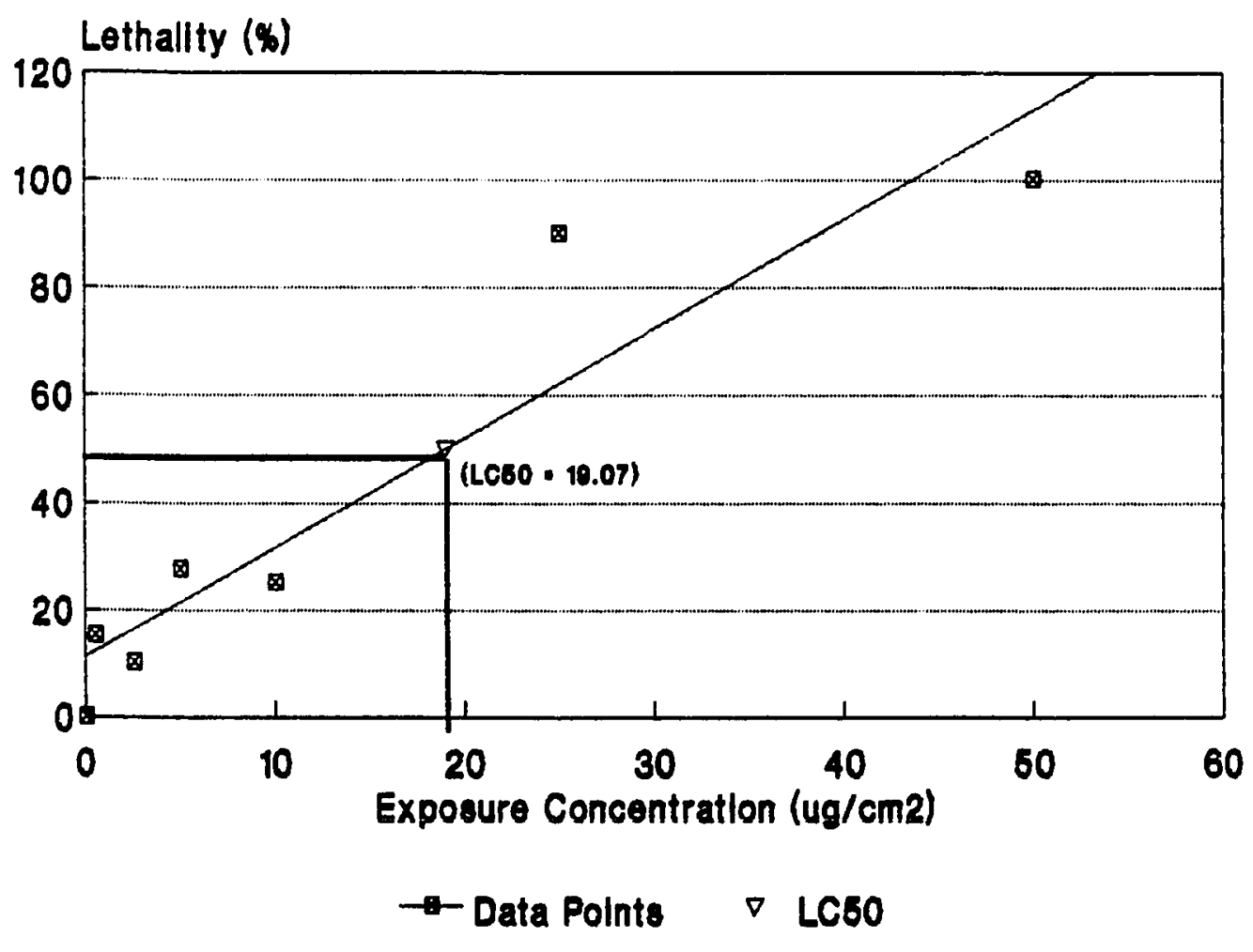

FIGURE 5 


\section{CHROMIUM TRIOXIDE LC50}

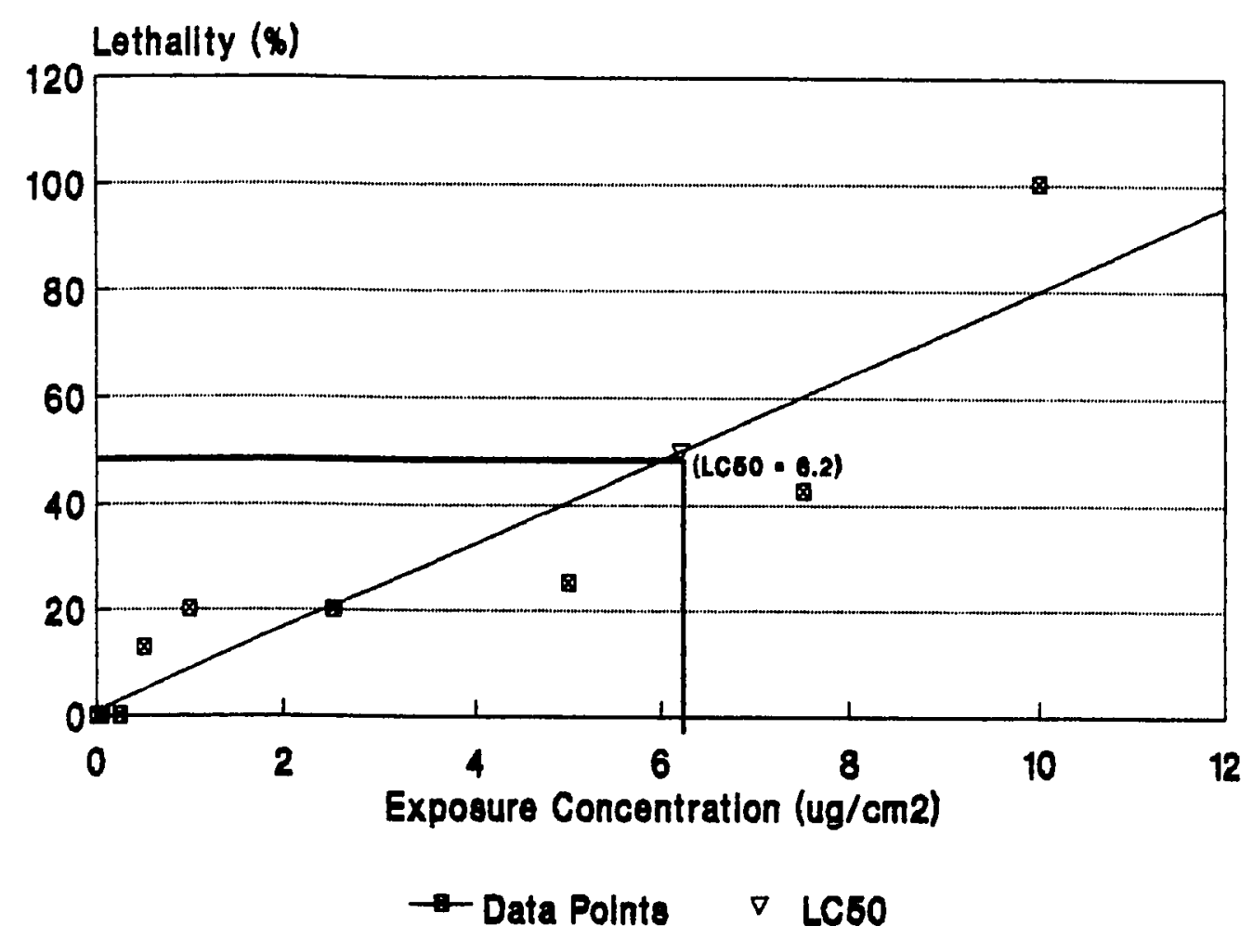

FIGURE 6 


\section{SELENIUM DIOXIDE}

LC50

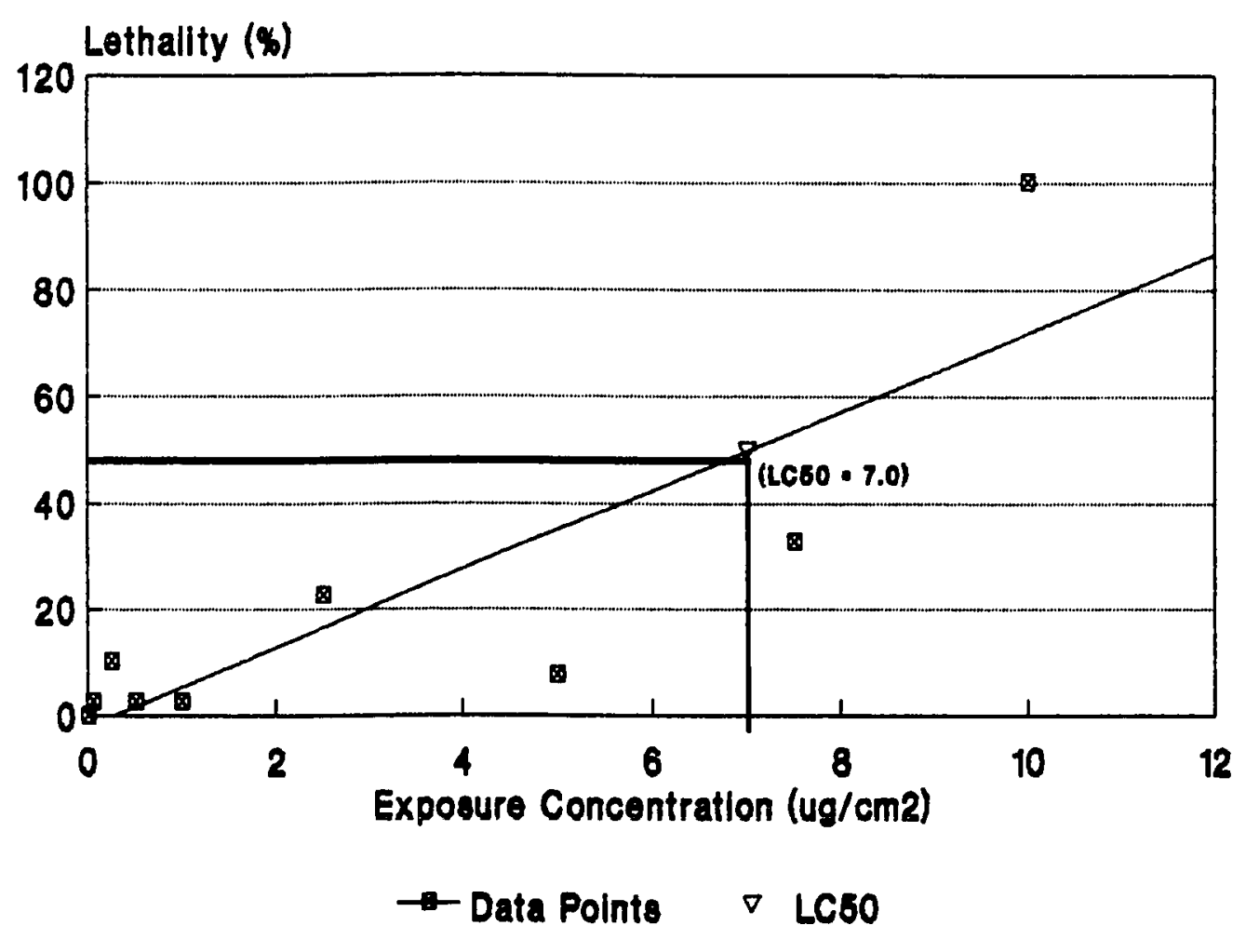

FIGURE 7 


\section{SODIUM SELENITE \\ LC50}

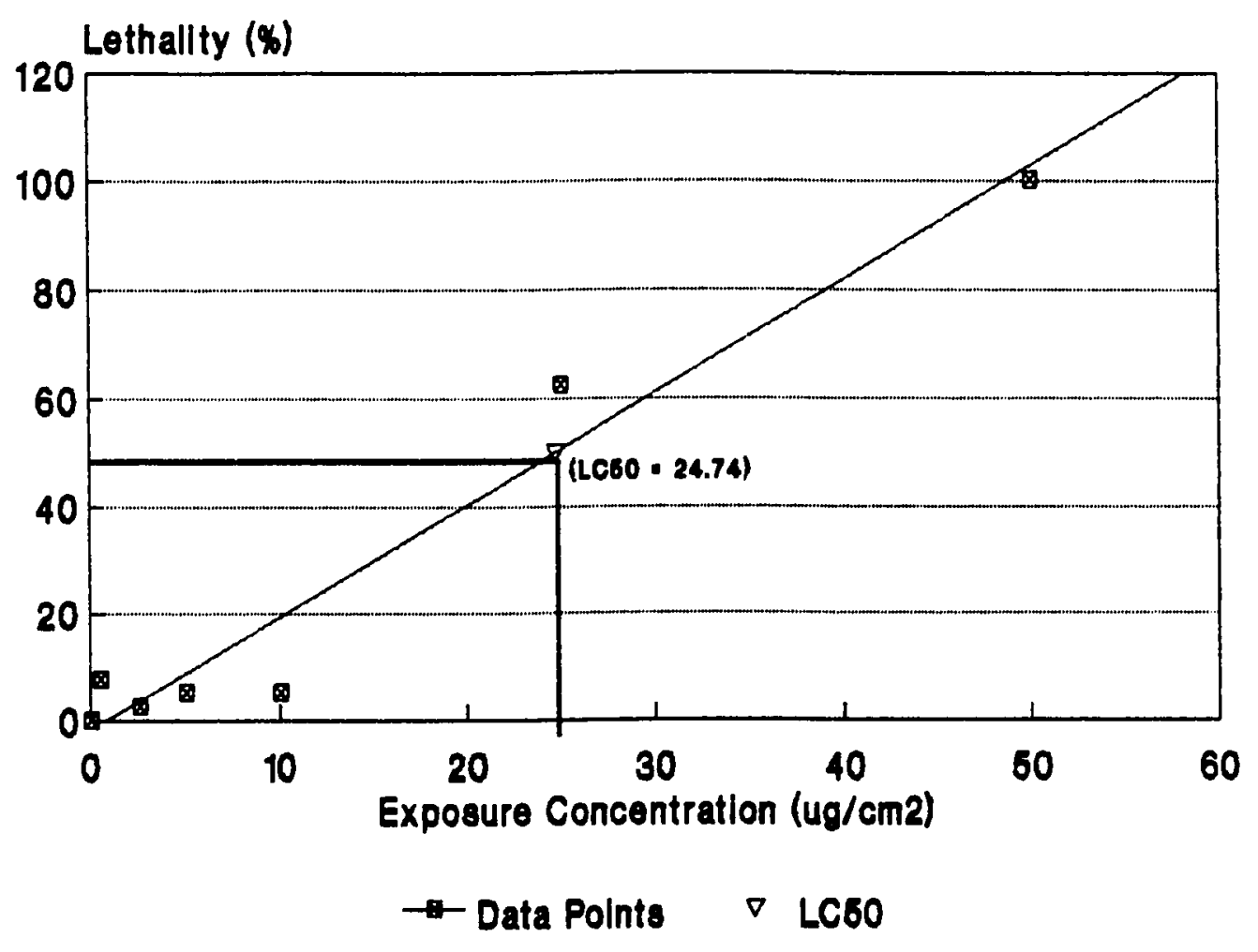

FIGURE 8 


\section{CHROMIUM CHLORIDE ELIMINATION}

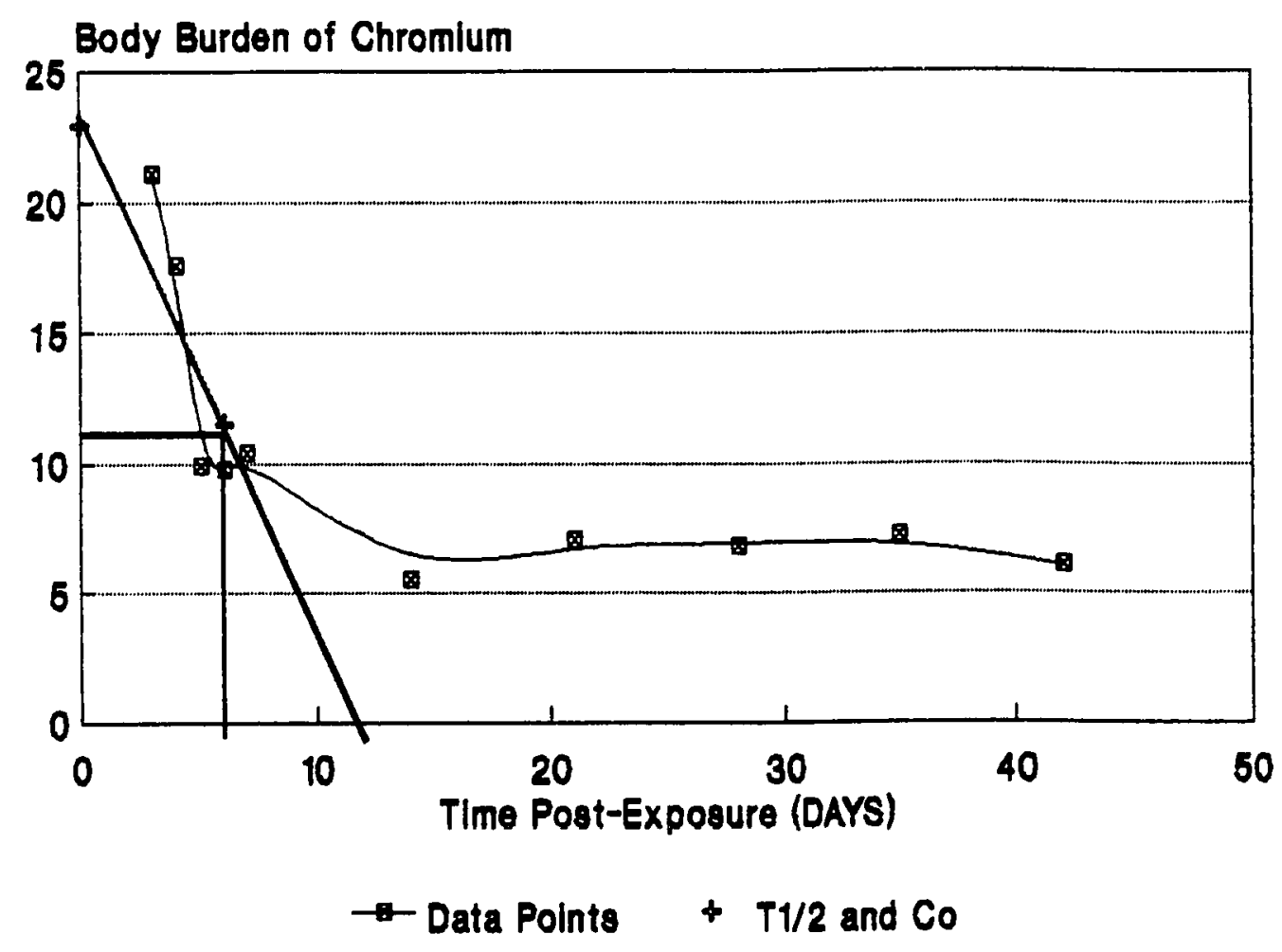

FIGURE 9 


\section{CHROMIUM TRIOXIDE ELIMINATION}

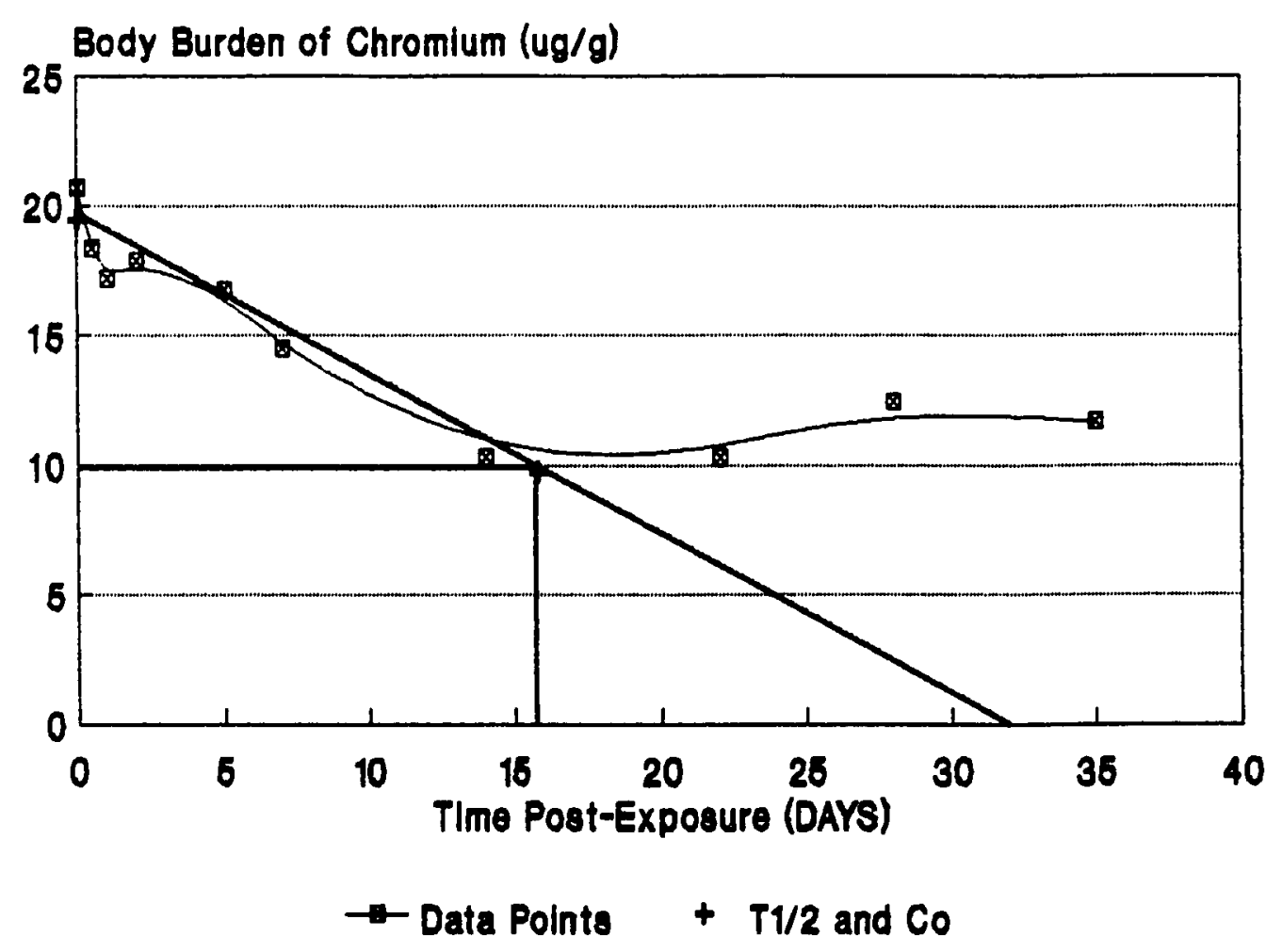

FIGURE 10 
SODIUM SELENITE ELIMINATION

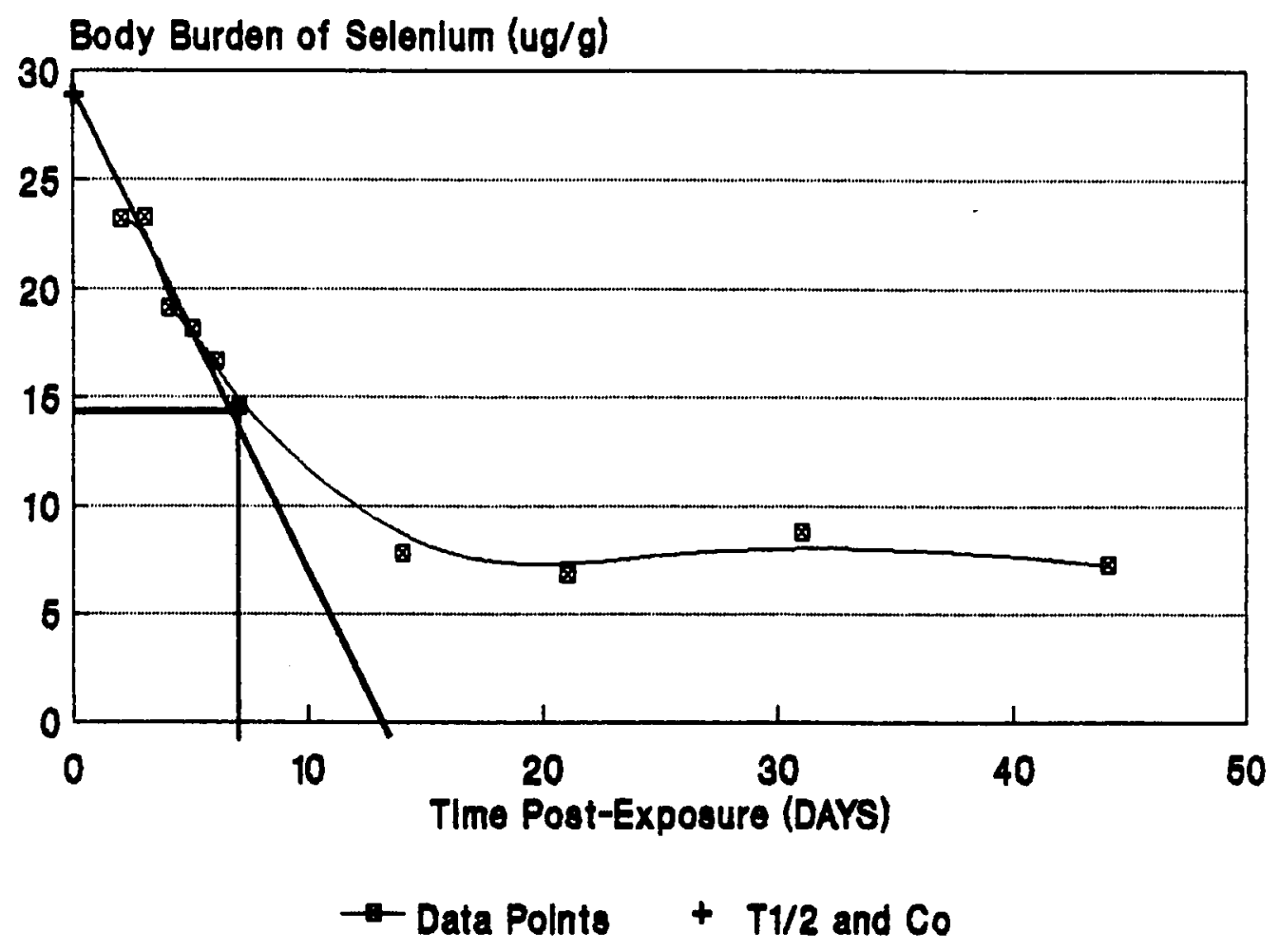

FIGURE 11 


\section{SELENIUM DIOXIDE ELIMINATION}

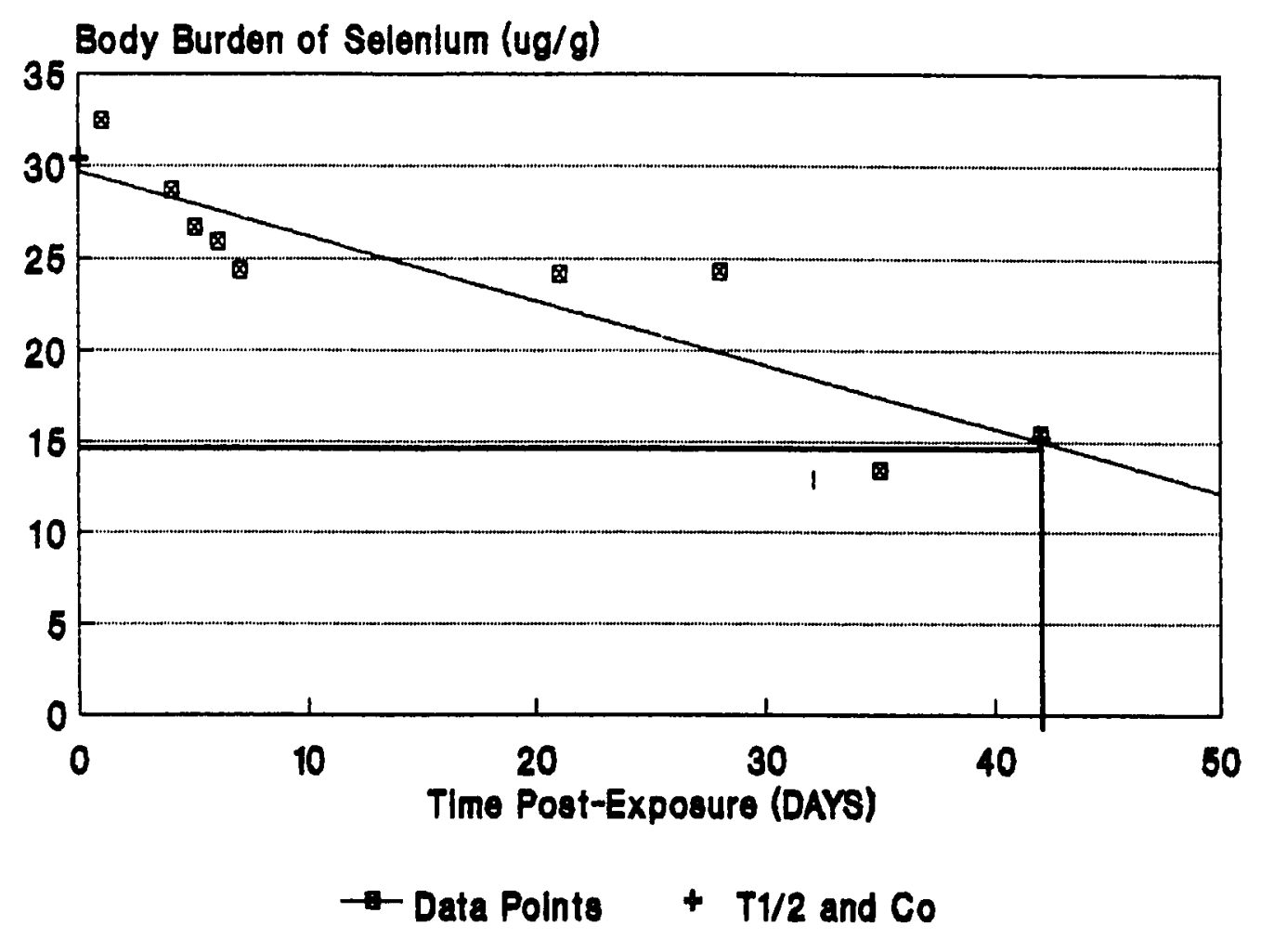

FIGURE 12 


\section{CHROMIUM CHLORIDE} ABSORPTION

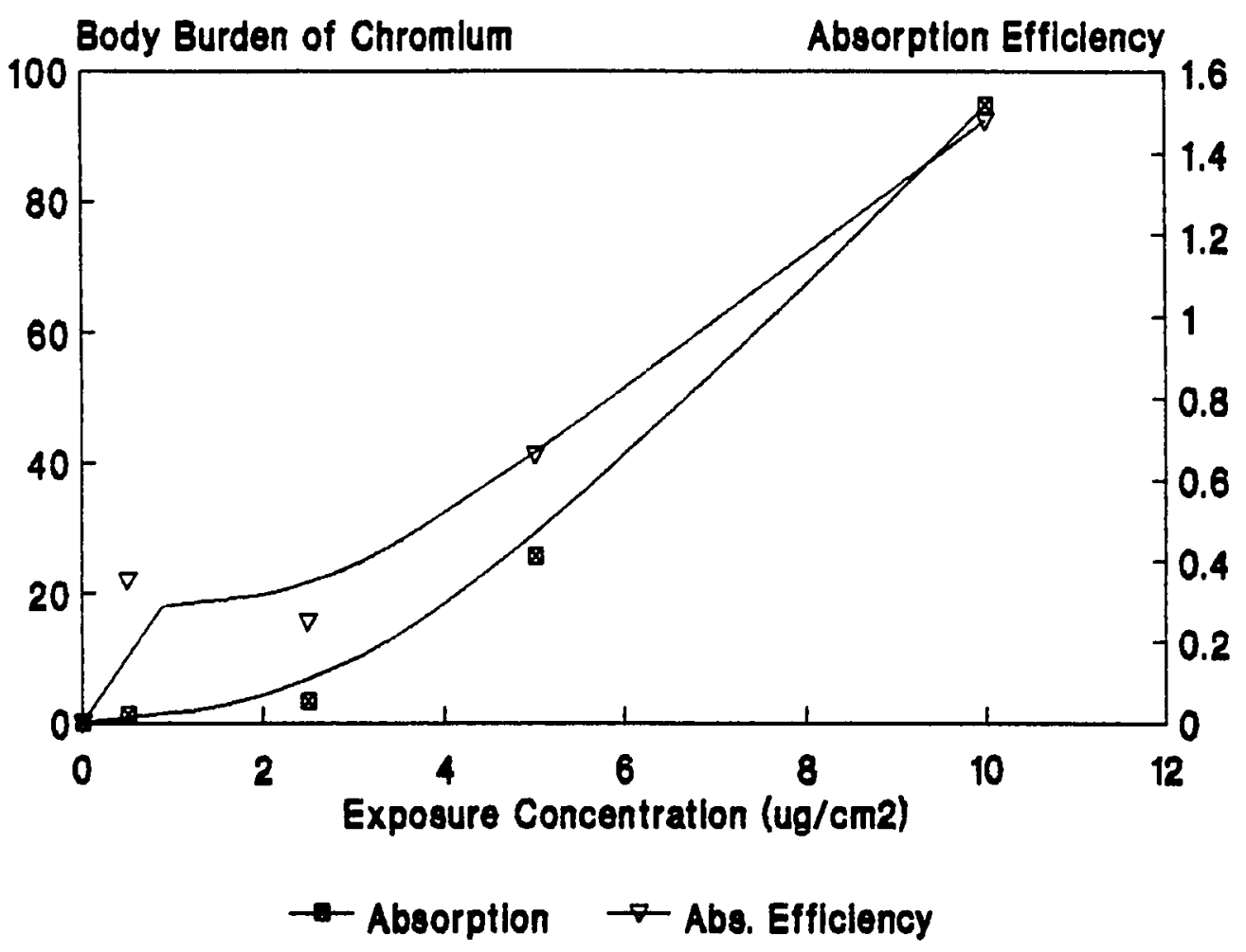

FIGURE 13 


\section{CHROMIUM TRIOXIDE ABSORPTION}

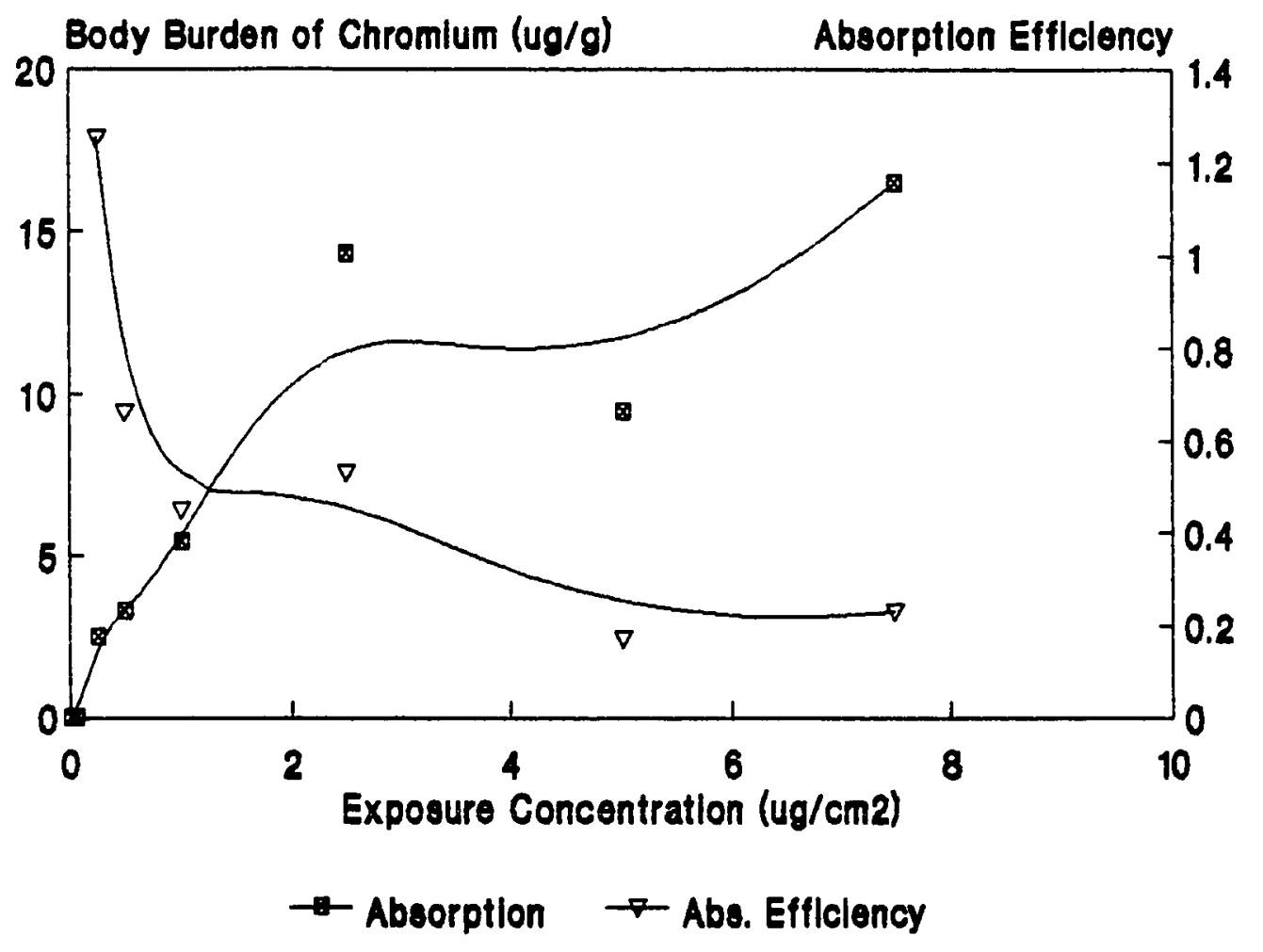

FIGURE 14 


\section{SELENIUM DIOXIDE}

ABSORPTION

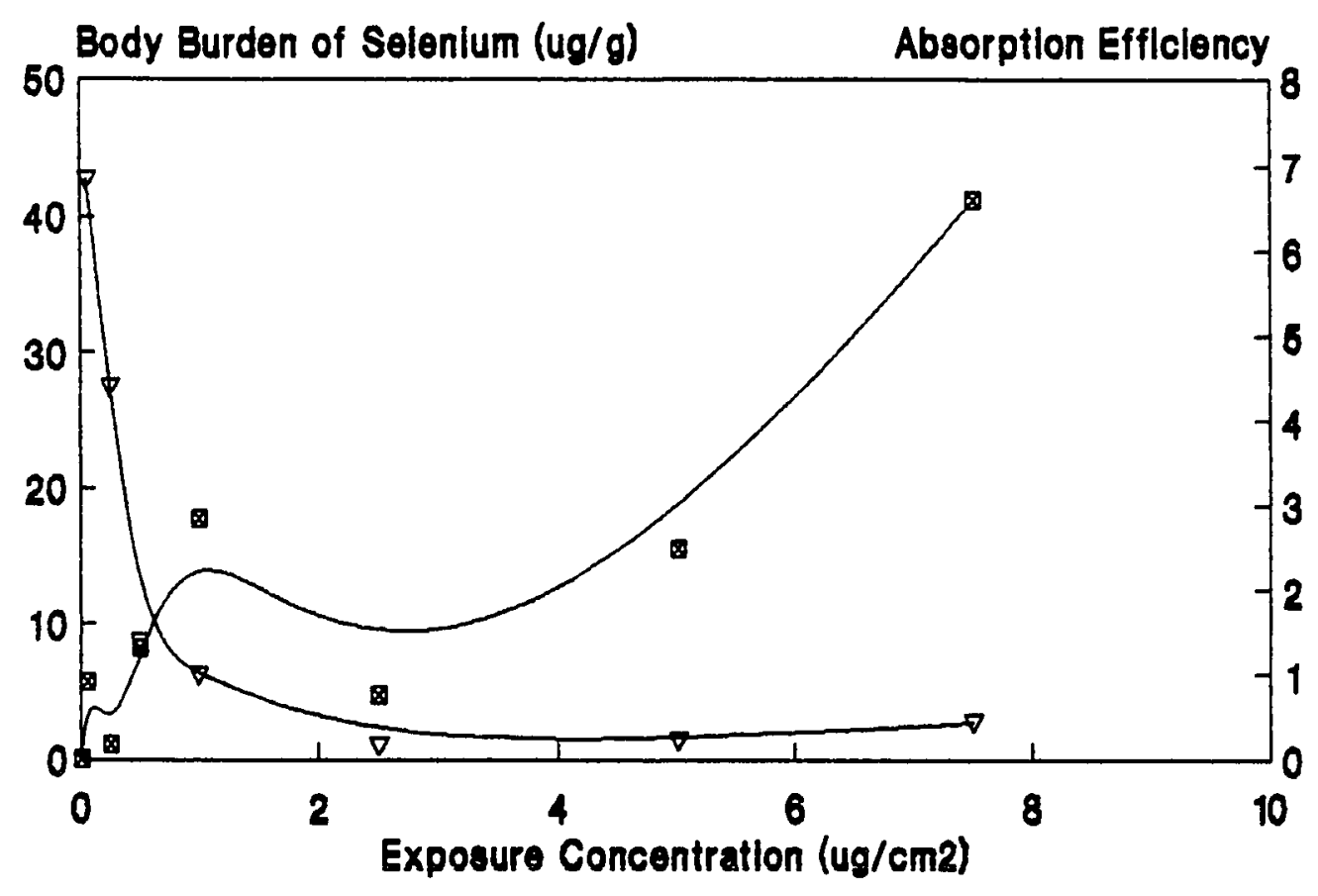

$\rightarrow$ Absorption $\rightarrow$ Abs. Efflclency 


\section{SODIUM SELENITE}

\section{ABSORPTION}

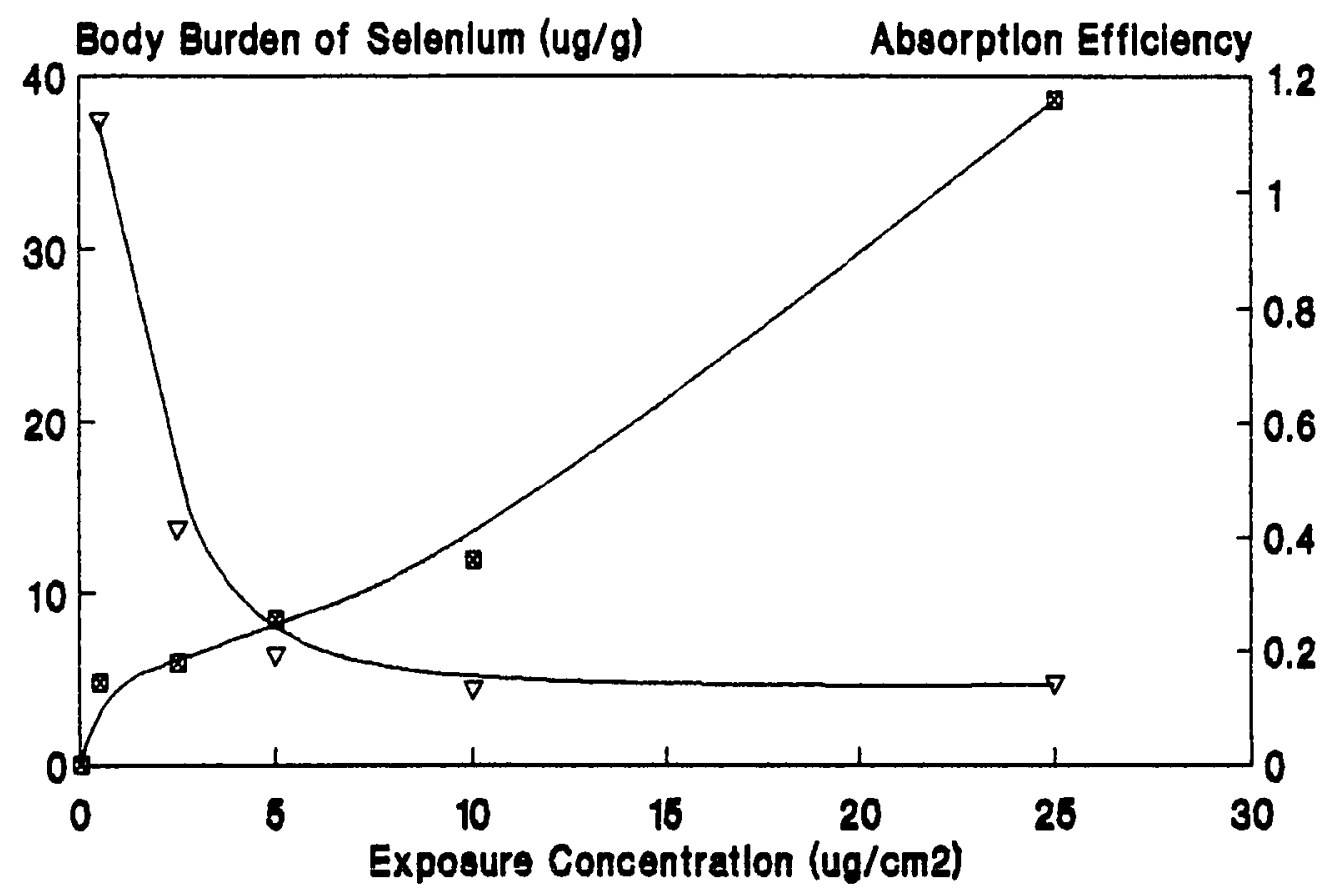

$\rightarrow$ Absorption $\rightarrow$ Abs. Efficiency

FIGURE 16 


\section{Combined Seleinium Absorption Efficiency}

\section{Selenium Dioxide and Sodium Selenite}

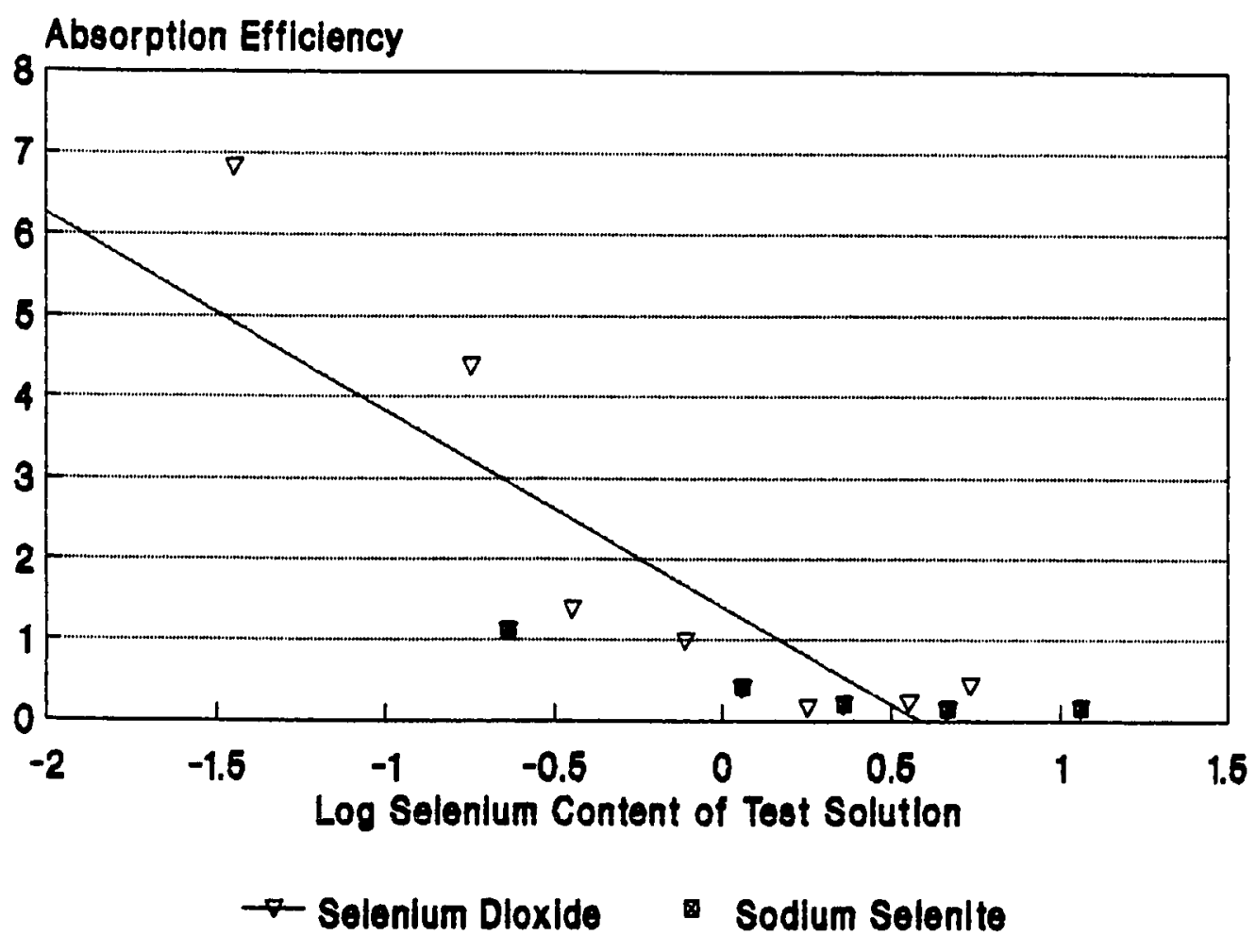

FIGURE 17 